\title{
A technology assessment of the proposed Cardiff-Weston tidal barrage, UK
}

\section{Geoffrey P. Hammond}

Professor, Department of Mechanical Engineering, University of Bath, Bath, UK; Institute for Sustainable Energy and the Environment, University of Bath, Bath, UK (corresponding author: ensgph@bath.ac.uk) (Orcid:0000-0002-0922-8728)

\section{Craig I. Jones}

Director, Circular Ecology Ltd, Bristol, UK

Rachel Spevack

Engineering Graduate, Department of Mechanical Engineering, University of Bath, Bath, UK

Several tidal power schemes have been proposed for the Severn estuary between south-west England and Wales, UK. In this paper the so-called Cardiff-Weston barrage is evaluated using various sustainability appraisal techniques to determine its net energy output, carbon dioxide footprint and financial investment criteria, alongside various critical technical and environmental issues. The barrage would be located seaward of the Severn Road crossings, involve an estimated cost of $\mathrm{f21}$ billion to construct and could potentially generate some 16.8 TWh/year - about 4.4\% of the UK electricity demand. An indicative energy technology assessment is undertaken to evaluate this tidal power scheme over its foreseen lifespan of 120 years in terms of its 'cradle-to-site', operation and maintenance requirements. The present analysis suggests that the proposed Cardiff-Weston barrage would yield relatively attractive 'figures of merit' in terms of its net energy and carbon dioxide emissions, although its financial performance is poorer than that of alternative power generators. Comparisons are also made with the much smaller Shoots barrage scheme proposed upstream of the Severn Road crossings, which is favoured by environmental groups due to its more benign ecological and environmental impacts.

\section{Notation}

$E_{\mathrm{con}, \mathrm{L}}$ total process energy invested in construction of the tidal barrage

$E_{\mathrm{dec}, \mathrm{L}}$ energy required to decommission the tidal barrage at the end of its life (L)

$E_{\text {mat,L }}$ total primary energy invested in materials used to construct the tidal barrage

$E_{\mathrm{n}, \mathrm{L}} \quad$ net electrical energy produced over the lifetime (L) of the tidal barrage

$E_{\mathrm{op}, \mathrm{L}} \quad$ energy required to operate the hydro-turbines over the lifetime (L) of the tidal barrage

$\mathrm{L} \quad$ lifetime of the tidal barrage (in years)

$R_{t} \quad$ net receipts (income less costs) from sale of electricity produced by a power generator

$t \quad$ time in years of the total foreseen life (L) of a power generator

\section{Introduction}

\subsection{Background}

Electricity generation presently contributes approximately $30 \%$ of UK carbon dioxide $\left(\mathrm{CO}_{2}\right)$ emissions (Alderson et al., 2012; Post, 2007), the principal greenhouse gas (GHG), having an atmospheric residence time of about 100 years (Hammond, 2000). Changes in atmospheric concentrations of GHGs affect the energy balance of the global climate system. Human activities have led to quite dramatic increases since 1950 in the basket of six GHGs incorporated in the Kyoto Protocol, which represent a $23 \%$ share of UK domestic GHG emissions in 2014 (CCC, 2015), mainly arising from the use of fossil-fuelled (coal and natural gas) power stations to generate electricity. GHG concentrations globally have increased from 330 to about 430 parts per million currently (IPCC, 2013). The cause of the observed rise in global average near-surface temperatures over the second half of the twentieth century has been a matter of dispute and controversy. But the most recent (2013) scientific assessment by the Intergovernmental Panel on Climate Change (IPCC) states that it is 'extremely likely' that humans are the dominant influence on the observed global warming since the mid-twentieth century (IPCC, 2013). The British government has therefore introduced a tough, legally binding target of reducing the nation's carbon dioxide emissions overall by $80 \%$ by 2050 in comparison with the 1990 baseline (DTI, 2007) in their Climate Change Act 2008. Achieving this carbon dioxide reduction target will require a challenging transition in the UK's systems for producing, delivering and using energy that is not only low carbon dioxide, but also secure and affordable, thus resolving the so-called energy policy trilemma (Hammond and Pearson, 2013).

The River Severn estuary lies between south-west England and Wales in the UK. It experiences the second largest tidal range $(\sim 14 \mathrm{~m})$ in the world (Binnie, 2016) and, over the years, a large number of private and UK government studies have looked for ways to harness the tidal power for electricity generation (Elliott, 2012; RCEP, 2000). This has recently been motivated by the growing concern over anthropogenic climate change and a desire to ensure a secure energy supply as fossil fuel use diminishes. The UK government has committed itself to both the $80 \%$ carbon dioxide reduction target (incorporated in its Climate Change Act 2008 ) and to achieving the EU target of at least $20 \%$ of its energy from renewable sources by 2020 (with $10 \%$ of 'green fuels', principally biofuels, for transport). A large-scale Severn Barrage tidal power scheme that would be operational by 2020 (DECC, 
A technology assessment of the proposed Cardiff-Weston tidal barrage, UK

Hammond, Jones and Spevack
2008) would have an estimated supply of $4 \cdot 4 \%$ of the total energy demand of the UK (SDC, 2007). This is the so-called Cardiff-Weston barrage (see Figure 1), often referred to as the Severn Barrage reference project, which would be constructed between Lavernock Point near the town of Barry (on the south Wales coast) and Brean Down in Somerset (adjacent to Westonsuper-Mare). Thus, by exploiting the tidal range in the Severn estuary, the UK could improve the energy diversity of its supply mix by way of such a renewable and sustainable source. A tidal power project in the Severn estuary could therefore make a significant contribution to reducing GHG emissions from the power sector, as well as helping to meet both international and domestic climate change targets (DECC et al., 2010a). What was, at the time, the UK government's Department of Energy and Climate Change (DECC) therefore shortlisted a number of tidal power schemes, including tidal range barrages, as well as some alternative, embryonic schemes which would take advantage of the tidal stream (such as those discussed by Binnie (2016)). The Cardiff-Weston barrage would be located seaward of the two Severn Road crossings, would involve an estimated cost of $£ 20.9$ billion to construct and could potentially generate some $16 \cdot 8 \mathrm{TWh} /$ year - about $4.4 \%$ of UK electricity demand. Binnie (2016) recently suggested that the Cardiff-Weston ebb generation barrage, together with the Bridgwater Bay and Swansea Bay tidal lagoons, could potentially supply $7 \%$ of UK energy demands. He also argued that this power supply would be predictable decades ahead and continuous from a 'whole-systems' perspective (i.e. if aligned with the tidal lagoons that have been proposed for locations on the north Wales coast and elsewhere in the UK).

\subsection{Major proposals for generating power in the Severn estuary}

A summary of the major tidal range barrage proposals for the Severn estuary is shown in Table 1. The Cardiff-Weston,
Beachley and Shoots barrage schemes were all shortlisted as part of a 2-year (2008-2010) cross-government Severn tidal power (STP) feasibility study instigated by the UK government (jointly with the South West Regional Development Agency and the Welsh Assembly government) of different Severn estuary tidal barrage and lagoon schemes (DECC et al., 2010a). Following this study, the new UK coalition government announced in October 2010 that it could not see a strategic case for public investment in an STP scheme in the immediate term, although private sector groups would continue to investigate the potential. The STP feasibility study found that the costs and risks for the British taxpayer and energy consumer were regarded as being too high in the financial situation at that time - that is, the post-2008 economic recession (DECC et al., 2010a). Thus, the UK government wished to keep the tidal barrage option open for future consideration. The decision not to rule out a scheme in the longer term recognises its significance as a large-scale UK energy resource. There were half a dozen substantive responses to this announcement from organisations such as the Bristol Port Company, the Countryside Council for Wales, the Environment Agency, World Wildlife Fund UK and the consulting engineering firm Parsons Brinckerhoff. They argued that work should start now to $(a)$ address the significant uncertainties and data gaps; (b) monitor the detailed baseline of distribution of animal species and habitats; (c) study fish behaviour and movement in the estuary; and $(d)$ assess measures to prevent or reduce possible environmental impacts. The present study of the Cardiff-Weston tidal power scheme thereby represents a contribution to this ongoing research effort.

A British parliamentary select committee (the House of Commons Energy and Climate Change Committee (HoC-ECCC, 2013)) investigated a new proposal by the now-defunct company Hafren Power Ltd (originally registered as Corlan Hafren - meaning

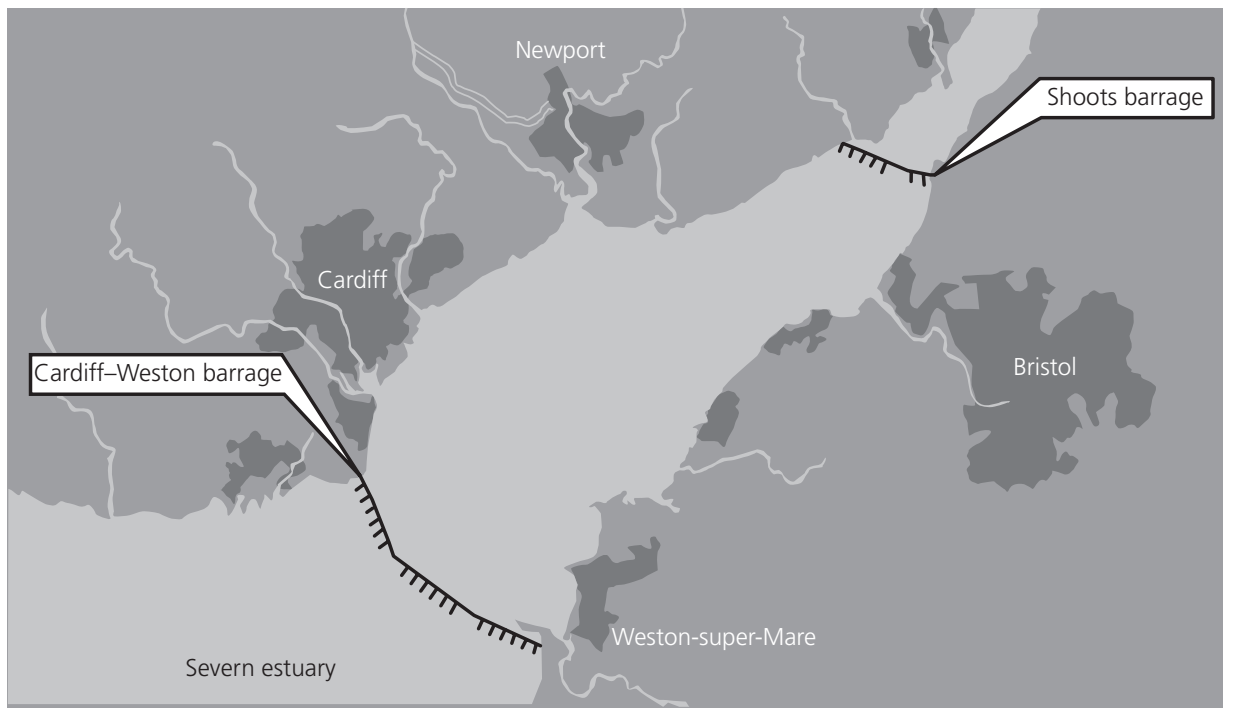

Figure 1. The locations of potential tidal power schemes in the Severn estuary (source: Hammond et al. (2014); adapted from SDC (2007)) 


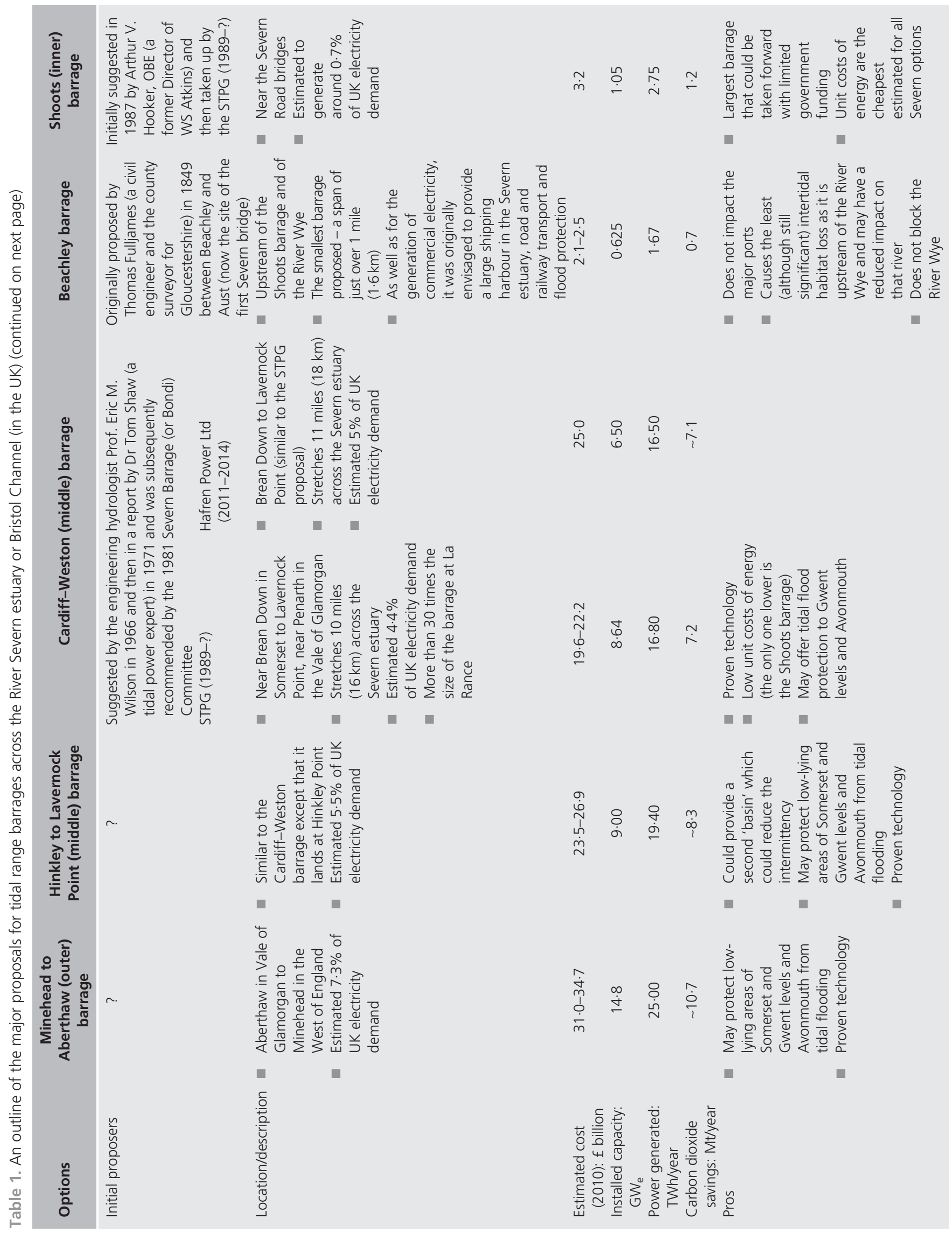




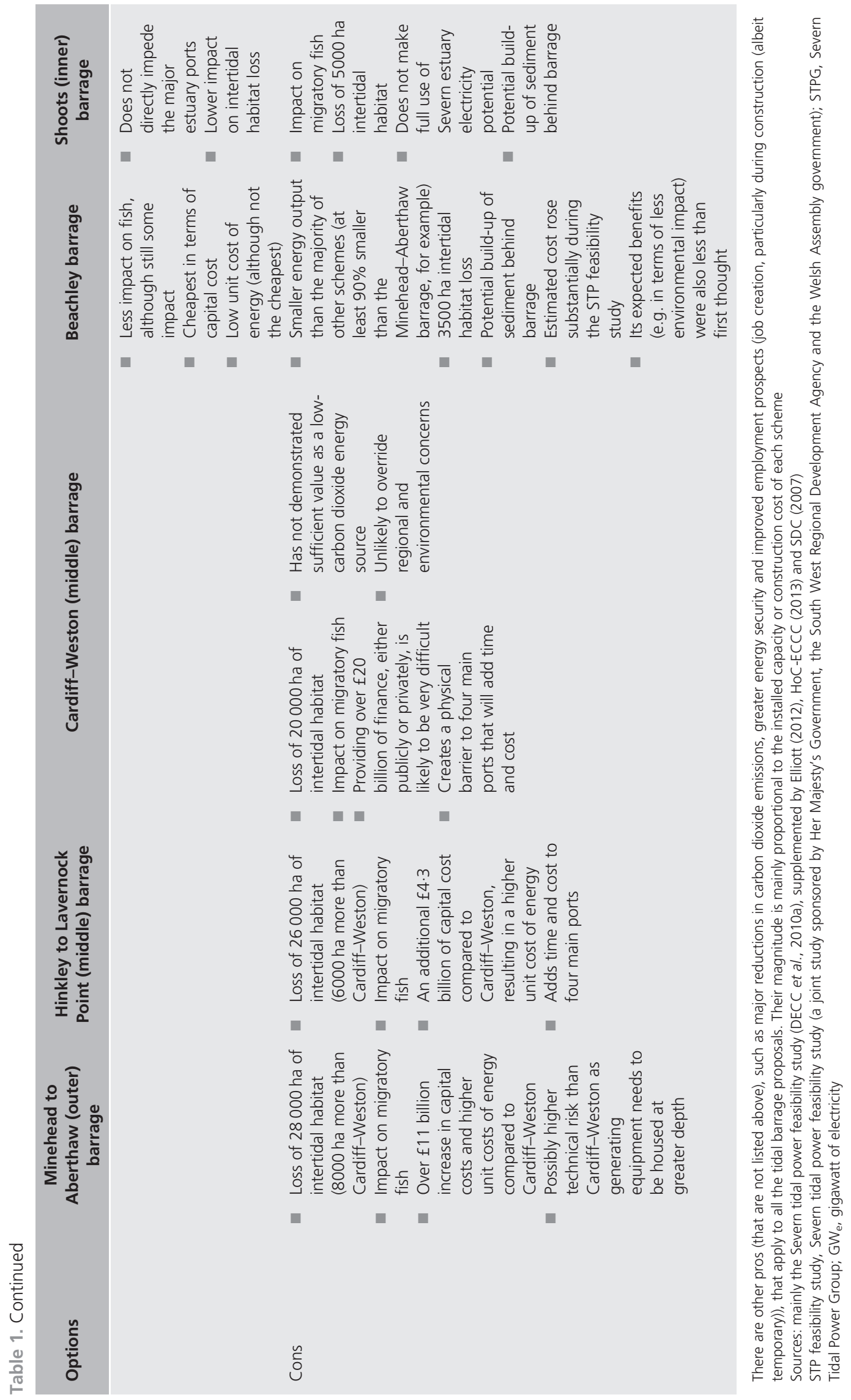


'Severn Group' in Welsh) to develop a slightly different variant of the Cardiff-Weston ('reference') tidal power scheme studied here and by the Sustainable Development Commission (SDC, 2007). It was apparently drawn up with the aid of several global engineering and construction firms: Mott MacDonald, URS, Bechtel and Arup. The scheme would have 1026 very-low-head bidirectional turbines, generating approximately $16.5 \mathrm{TWh} /$ year on both ebb and flood tides. As a major proposal, the HoC-ECCC sought to examine the feasibility of the scheme to encourage transparency and public debate (HoC-ECCC, 2013). HoC-ECCC (2013) acknowledged that such a large-scale project might contribute to reducing the carbon dioxide emissions of ('decarbonising') the UK energy sector, provide energy security benefits and create jobs. However, the committee was not convinced that the economic case for the proposed barrage was strong enough, or that Hafren Power had adequately answered what they regarded as serious ecological and environmental concerns about the potential barrage (HoC-ECCC, 2013). Subsequently, the UK government has ruled out proceeding with Hafren Power's plan for a tidal range barrage across the Severn estuary, at least until the developer could put together a more convincing case for the $£ 25$ billion scheme (see again Table 1). It was announced in January 2014 that the company chief executive officer had resigned and the firm became 'dormant', effectively putting an end to this variant of the project.

In addition to tidal range barrages, the STP feasibility study evaluated two tidal lagoon proposals: the Fleming (or Welsh Grounds) lagoon, covering $28 \mathrm{~km}$ of the Welsh shoreline of the Severn estuary between Newport and the Severn Road crossings, and the Bridgwater Bay shoreline and offshore lagoons. A shoreline tidal lagoon, or 'bounded reservoir', is formed by a Ushaped breakwater or 'bund wall', built out from the coastline, into which a bank of hydroturbines is inserted (DECC et al., 2010a; Elliott, 2012; SDC, 2007). In contrast, an offshore tidal lagoon is constructed of roughly circular low-head dams, rather like causeways with rock infill, in open seawater (Elliott, 2012). The turbines generate electricity on both the incoming and outgoing tides, four times a day, as the seawater fills up and empties from the lagoon with the rise and fall of the tides. Such projects have the advantage, compared to tidal barrages, of not blocking off the estuary. Thus, they would not interfere significantly with shipping lanes and should have lower ecological impact (Elliott, 2012). The Bridgwater Bay shoreline lagoon would be sited between Hinkley Point and Weston-super-Mare. A tidal fence between Minehead and Aberthaw, the site of the outer barrage proposal (see Table 1), was also examined as part of the STP feasibility study. The latter study found that the Cardiff-Weston and Shoots tidal range barrages held out the most promise, along with the Bridgwater Bay lagoon. It recognised that the Cardiff-Weston barrage and the Bridgwater Bay lagoon were capable of being combined (DECC et al., 2010a). However, it was observed that the environmental impact of such combinations would be greater than that of the largest stand-alone scheme. The STP feasibility study finally concluded that the Cardiff-Weston (reference) barrage would make the best use of the tidal resources of the Severn estuary and would be the most costeffective scheme (DECC et al., 2010a). More recently, a proposal to build a 'pathfinder' shoreline tidal lagoon, with a $15 \mathrm{~km}$ long sea wall, in Swansea Bay was made by Tidal Lagoon Power (together with a number of major delivery partners, including Atkins, General Electric, Andritz Hydro, Laing O'Rourke and Alun Griffiths Ltd), and this is currently (2016) being given serious consideration by the present UK government. It regards the scheme as 'exciting', but involves an 'untested technology' that needs to be carefully reviewed.

\subsection{Issues considered}

There is a range of opinions in the literature about how to trade off different sustainability criteria against each other. Hammond and Jones (2011a), for example, noted that a number of diverse attempts have been made to integrate sustainability perspectives. These include simple sustainability checklists, 'ecological' or environmental 'footprinting', multicriteria decision analysis (MCDA), sustainability maps or 'tortilla' diagrams and a qualitative sustainability appraisal framework (as advocated by the UK sustainability non-governmental organisation Forum for the Future, founded by Sara Parkin and Jonathan Porritt). MCDA, for example, typically aggregates various distinct impacts arising from alternative technological options. Allen et al. (2008) therefore argued that there are several reasons for discouraging such aggregate methods (including, among them, cost-benefit analysis (CBA)). Decision makers are presented with a single, aggregate decision criterion, which actually hides many disparate environmental impacts. Consequently, Allen et al. (2008) suggested that it is vitally important that the implications of, and trade-offs between, these impacts are faced, particularly by politicians, rather than obscured by the methodology. Various energy and ecological/environmental factors that relate to tidal power projects have been evaluated in the present study without any attempt to trade them off against each other. That is left to future national or regional decision makers.

An indicative technology assessment has been conducted on the 'cradle-to-site,' operational and maintenance energy and related requirements for the Cardiff-Weston reference tidal range barrage (see the location depicted in Figure 1). An 'integrated approach' was used (similar to that of, for example, Allen et al. (2008)) to assess the impact of this scheme, employing both energy analysis (EA) and carbon dioxide accounting applied on a 'life cycle' or whole-systems basis from 'cradle to grave', alongside related financial investment appraisal. EA required estimates of the energy outputs of the power generators during use and the energy requirements for their construction and operation. The total energy output of the scheme over its foreseen lifespan of 120 years was estimated to determine the associated energy gain ratios (EGRs) and energy payback periods (EPPs). But carbon dioxide footprints have become the 'currency' of debate in a climate-constrained world (Alderson et al., 2012). They represent the amount of carbon dioxide-equivalent emissions associated with a given activity or community and are generally presented in terms of units of mass or weight (kilograms per functional unit (e.g. kilograms carbon dioxide 
equivalent $/ \mathrm{kWh}$ )). Embodied energy and carbon dioxide appropriate to the various power generators specified in the current work were determined using the Inventory on Carbon and Energy (ICE) (developed at the University of Bath (Hammond and Jones, 2008, 2011b)). 'Embodied energy' is here defined as the total primary energy consumed from direct and indirect processes associated with power production and within the boundary of cradle-to-site (Hammond and Jones, 2011b). This includes all activities from material extraction (quarrying/mining), manufacturing, transportation and right through fabrication processes until the power plant is constructed for operational use. Similarly, 'embodied carbon dioxide' is the sum of fuel-related carbon dioxide emissions (i.e. embodied energy which is combusted, but not the feedstock energy which is retained within materials) and process-related carbon dioxide emissions (Hammond and Jones, 2011b).

The present contribution is part of an ongoing research effort aimed at evaluating and optimising the performance of alternative (sustainable, centralised and distributed) energy technologies for the UK (Allen et al., 2008; Cheng and Hammond, 2016; El-Fadel et al., 2010; Hammond et al., 2011, 2012) in the context of transition pathways to a low-carbon dioxide future for the UK (Hammond and Pearson, 2013; Hammond et al., 2013). Here the Cardiff-Weston tidal power scheme has been evaluated using various appraisal techniques to determine its net energy output, carbon dioxide footprint and financial investment parameters, alongside some critical technical and environmental issues. This study is 'indicative' in the sense of being a simplified evaluation and illustration of the performance of this tidal power scheme in the light of imperfect information. Thus, the uncertainties involved are quite large, because of the rough estimates available at the concept design stage of the proposal. Nevertheless, such assessments provide a valuable evidence base for developers, policymakers and other stakeholders. Comparisons are also made with the much smaller Shoots barrage scheme (costing about $£ 3 \cdot 2$ billion to construct and could generate around $2.75 \mathrm{TWh} /$ year (or a little under $1 \%$ of UK electricity demand)) that would be located upriver of the Severn Road crossings (see again Figure 1), which is favoured by several environmental groups because of its more benign ecological and environmental impacts (Hammond et al., 2014).

\section{Cardiff-Weston tidal power barrage scheme}

\subsection{Overview of the scheme}

The Cardiff-Weston barrage would constitute a scheme with 8.64 GW of electrical energy $\left(\mathrm{GW}_{\mathrm{e}}\right)$ and extending from Lavernock Point on the south Wales coast to Brean Down on the Somerset coast (see Figure 1). This scheme was extensively evaluated by the Severn Tidal Power Group (STPG, 1986), a consortium of engineering and construction companies (comprising Balfour Beatty, Taylor Woodrow, Sir Robert McAlpine and Alstom) formed in 1981. They studied this barrage in some detail, alongside the smaller Shoots barrage (see also Hammond et al. (2014)). The Cardiff-Weston barrage is often referred to as the "main Severn barrage proposal' (SDC , 2007) as it has been examined in the most detail. In previous studies, including the STPG report (1986), this has been deemed one of the most favourable schemes, potentially generating some $4 \cdot 4 \%$ of the total UK electricity supply (SDC, 2007), while it is likely to give rise to less extreme environmental impacts relative to larger schemes, such as the Minehead-Aberthaw barrage (an alternative $14.8 \mathrm{GW}_{\mathrm{e}}$ scheme; located seaward of the Cardiff-Weston site shown in Figure 1). It is thought that the Cardiff-Weston scheme would still lead to a reduction in water levels and tidal range and, due to the loss of intertidal habitat, the bird and fish populations in the River Severn and its estuary are likely to decline. Benefits of this scheme include protection from storm surges and sea level rise. The Severn estuary directly feeds four industrial shipping ports at Bristol, Cardiff, Newport and Sharpness, all of which could be directly affected by a barrage both during and after the construction period (see also Binnie (2016)).

The proposed scheme (outlined in Table 2) was more recently examined by the UK government's independent SDC (2007), established by the then-Labour government in 2000 (although the subsequent coalition government withdrew funding after coming to power in 2010, and the SDC had to close in March 2011). They estimated that the STPG Cardiff-Weston barrage scheme would generate an output of around $16.8 \mathrm{TWh} /$ year and consist of 216 bulb, fixed distributor hydroturbines with both ebb generation and 'flood pumping' (see Figure 2). Each turbine would have a nominal rated capacity of $40 \mathrm{MW}$ at 0.9 power factor in $9 \mathrm{~m}$ dia. runners and turbine technology similar to that adopted for the $740 \mathrm{~m}$ long La Rance tidal barrage in Brittany, near Saint-Malo, in France (Elliott, 2012). The latter scheme was built over the period 1961-1967, and the first output from the $240 \mathrm{MW}$ capacity

Table 2. Outline features of the proposed Cardiff-Weston tidal barrage scheme

$\begin{array}{lc}\text { Length of embankments } & 16 \cdot 1 \mathrm{~km} \\ \text { Generating capacity } & 8 \cdot 64 \mathrm{GW}(8640 \mathrm{MW}) \\ \text { Annual average electricity output } & 16 \cdot 8 \mathrm{TWh}(16800 \mathrm{GWh}) \\ \text { Number of turbines } & 216 \\ \text { Number of sluice openings } & 166 \\ \text { Ship lock size } & 360 \mathrm{~m} \times 50 \mathrm{~m}(\times 2)\end{array}$

Source: SDC (2007)

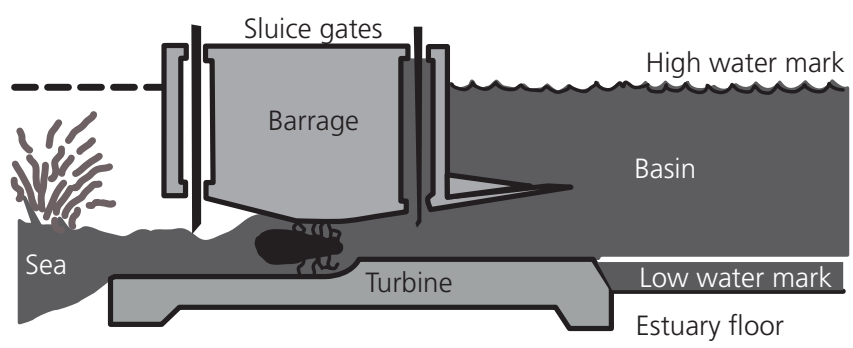

Figure 2. The 'Cardiff-Weston' tidal barrage: a schematic diagram based on an ebb-generating turbine with 'flood pumping' (source: adapted from REUK (2017)) 
turbines (each of $10 \mathrm{MW}$ ) occurred in 1966. They operate in a reversible, or two-way, mode with a tidal range of up to $12 \mathrm{~m}$. The Cardiff-Weston barrage itself would employ existing civil engineering construction methods, based on caissons built in situ within a cofferdam (Elliott, 2012). Significant dredging would be required in the approach channel to the ship lock and also to prepare the foundations for the barrage. The embankments would primarily be placed using a seagoing plant.

Ebb generation utilises the incoming tide, which is permitted to pass through sluice gates embedded in the barrage. Estuarine water is thereby trapped behind the barrage at high tide by way of closed sluices. The outgoing, or 'ebb', tide produced by the resulting head then generates electricity as it passes through the hydroturbines (Elliott, 2012). In contrast, flood generation uses the incoming tide to generate electricity. The envisaged $16 \cdot 1 \mathrm{~km}$ long Cardiff-Weston barrage (SDC, 2007) would employ both ebb generation and flood pumping. Under the latter mode, the hydroturbines run in reverse and act like motor-pump sets to drive additional water behind the barrage into the basin at high tide (Elliott, 2012). This yields extra water for the subsequent ebb generation cycle. Links to the shore and national grid would require $400 \mathrm{kV}$ transmission lines. In contrast, the $4.1 \mathrm{~km}$ long Shoots barrage scheme would use 'Straflo', or rim generator, turbines operating solely through ebb generation (Elliott, 2012; Hammond et al., 2014), potentially generating some $2.75 \mathrm{TWh} /$ year.

\subsection{Construction methods and costs}

The STPG produced a follow-up 1989 report (STPG, 1989) that remains the most detailed study into an appropriate construction method which could be used to build the Cardiff-Weston barrage. Much of the data used in the later studies, such as those in the Parsons Brinckerhoff/Black \& Veatch options analysis report for the DECC (2008), have been taken directly from the 1989 report, including material quantities and construction methods. The final layout of the proposed scheme would comprise sluice caissons and turbine caissons joined by plain caissons. All of these caissons would be constructed in the dry in work yards and then towed to the site and sunk into place (SDC, 2007). This is a proven method - similar techniques were used to build Mulberry harbours for the D-Day landings in World War II. The barrage at La Rance was constructed by assembling 'cofferdams' upstream and downstream of the barrage site, such that it could be constructed in the dry. But this caused significant environmental damage, and this method would not be tolerated today. It was also an expensive, lengthy process which, if used in the Severn, would adversely affect shipping to ports upstream of the barrage (SDC, 2007). The main ship lock, sited near the Lavernock Point side of the Cardiff-Weston barrage, would therefore be built from 12 specialist caissons which would be towed into place, as would an additional small-craft lock on the Brean Down side. Significant dredging would be required in the approach channel to the ship lock and also to prepare the foundations for the barrage. The embankments would primarily be put in place using seagoing plant, such as barges.
The Cardiff-Weston barrage was assumed (DECC, 2008; SDC, 2007; STPG, 1989) to begin to generate $50 \%$ of its total power 6 years after the start of construction, as construction work was presumed to have been completed during that year. In year 2 of operation, the scheme would operate at $75 \%$ capacity, rising to $100 \%$ from year 3 onwards. The Parsons Brinckerhoff/Black \& Veatch options analysis report (DECC, 2008) also includes a 4-year preconstruction period, during which the final design would be drawn up and planning consent obtained. The construction cost adopted here was based on the STPG 1989 report for the then-Department of Energy (STPG, 1989). This was reappraised for the Parsons Brinckerhoff/Black \& Veatch options analysis report (DECC, 2008) and updated to 2008 monetary values by using the construction output price index (Copi). It has been assumed that there has been no 'real terms' increase in these figures between 2008 and the 2010 baseline, due to the levelling of the Copi. The financial results of the presented study are therefore given in pounds sterling (2010). (Conversion rates applying in May 2010 were US\$1 $\approx £ 0.655$ and $€ 1 \approx £ 0.869$.) DECC published 'cash flow' figures running up to 2050, which provide a breakdown of the capital cost; constant real terms annual preconstruction and construction costs have been assumed. However, the STPG reports (STPG, 1986, 1989) broke these estimates down by year as the work completed in each year will vary. The proportions of the total capital cost spent each year in these two detailed construction breakdowns have been applied to the most recent DECC capital cost estimate. The cash flow over the barrage construction period does have an impact on the final levelised cost calculated for the Cardiff-Weston scheme. In the present study, no cost allowance has been made for a public road or a train link in line with the DECC study (2008).

\subsection{Maintenance, operation and decommissioning}

The methods used to calculate the maintenance and operational costs of tidal barrages in the UK vary between different reports. The most recent study of the Cardiff-Weston scheme for the DECC (2008) presents the worst case, suggesting $70 \%$ of the present value of supply, installation and commissioning costs of mechanical and electrical (M\&E) equipment is incurred every 40 years. The cost of the turbine generators has been estimated to be $£ 5841$ million in the Parsons Brinckerhoff/Black \& Veatch options analysis report (DECC, 2008), equating to $£ 817$ million per annum over the 5-year maintenance period. To calculate equivalent carbon dioxide emissions and energy consumption during this period, $70 \%$ of the total emissions associated with the M\&E equipment employed for the Cardiff-Weston barrage were adopted as a working assumption. Parsons Brinckerhoff/Black \& Veatch (DECC, 2008) utilised a value of $1.75 \%$ of the total construction cost as the annual maintenance cost of the project, equating to $£ 314$ million. This figure remains constant even when the barrage is running at only $25 \%$ total output over the maintenance years. In general, the costs associated with the decommissioning of a Cardiff-Weston barrage have been excluded from this study - this is in line with all previous studies of UK tidal barrage schemes. The decision to disregard this (potentially significant) item is due to the long design life (120 years) of the 
barrage. Attitudes to recycling have changed dramatically over the past 120 years, as have recycling methods. Consequently, it is difficult to predict how future generations would wish to dispose of such a barrage.

\section{Energy analysis}

\subsection{Methodology}

To determine the primary energy inputs needed to produce a given artefact or service, it is necessary to trace the flow of energy through the relevant industrial sector (Allen et al., 2008; Cheng and Hammond, 2016; El-Fadel et al., 2010; Hammond and Winnett, 2006; Hammond et al., 2012, 2013; Udo de Haes and Heijungs, 2007). This is based on the first law of thermodynamics (the principle of conservation of energy) or the notion of an energy balance applied to the system. Thus, the sum of all the outputs from this system multiplied by their individual energy requirements must be equal to the sum of inputs multiplied by their individual requirements. The system boundary should strictly encompass the energy resource in the ground (Chapman, 1974; Roberts, 1978; Slesser, 1978) (known as the 'cradle' - for example, oil in the well or coal at the mine). In the present analysis, the downstream boundary is known as the 'site' (hence, cradle-to-site (Hammond and Jones, 2011b; Hammond et al., 2013)), which, in this case, is represented by the national electricity network (operated by the transmission network operators and distribution network operators). Consequently, it effectively accounts for all UK power sector primary energy use (and associated emissions). EA yields the so-called gross energy requirement of the product or service system (Chapman, 1974; Hammond and Jones, 2008; Roberts, 1978; Slesser, 1978). The EA process consequently implies the identification of feedback loops, such as the indirect or 'embodied' energy requirements for material and capital inputs. Several differing methods of EA have been developed (see Figure 3), the most significant being statistical analysis, input-output analysis, process analysis (or energy 'flow charting') and hybrid analysis (Chapman, 1974; Cheng and Hammond, 2016; Hammond and Jones, 2008; Roberts, 1978; Slesser, 1978).

\subsection{Application of energy analysis to the Cardiff-Weston barrage}

EA, as indicated earlier, is an established method of tracing the flow of energy through a system (Allen et al., 2008; Chapman, 1974; Cheng and Hammond, 2016; El-Fadel et al., 2010; Hammond and Jones, 2008; Hammond et al., 2012, 2013; Roberts, 1978; Slesser, 1978) and can be readily applied to large-scale civil engineering projects. The present analysis has been conducted to assess and compare the envisaged energy benefits of the proposed Cardiff-Weston barrage scheme as a more benign option for the generation of electricity than those from fossil fuels. The methods used to carry out an EA mainly stem from studies completed in the 1970s (e.g. Chapman (1974), Roberts (1978), Slesser (1978)). They can account for, and hence suggest ways to reduce, the energy consumed and expended over the lifetime of the system under consideration. This includes the embodied energy of the raw materials, transportation, construction, maintenance, operation and decommissioning. The stages investigated in the process of EA employed here, and the system boundary adopted, are illustrated in Figure 4. Inevitably, there were limited data available for some processes; therefore, simplifying assumptions needed to be made. However, the excluded processes were found to have an insignificant impact on the life-cycle energy requirements of the barrage.

Component fabrication, which has been left out of the present study (as indicated again in Figure 4), refers specifically to the

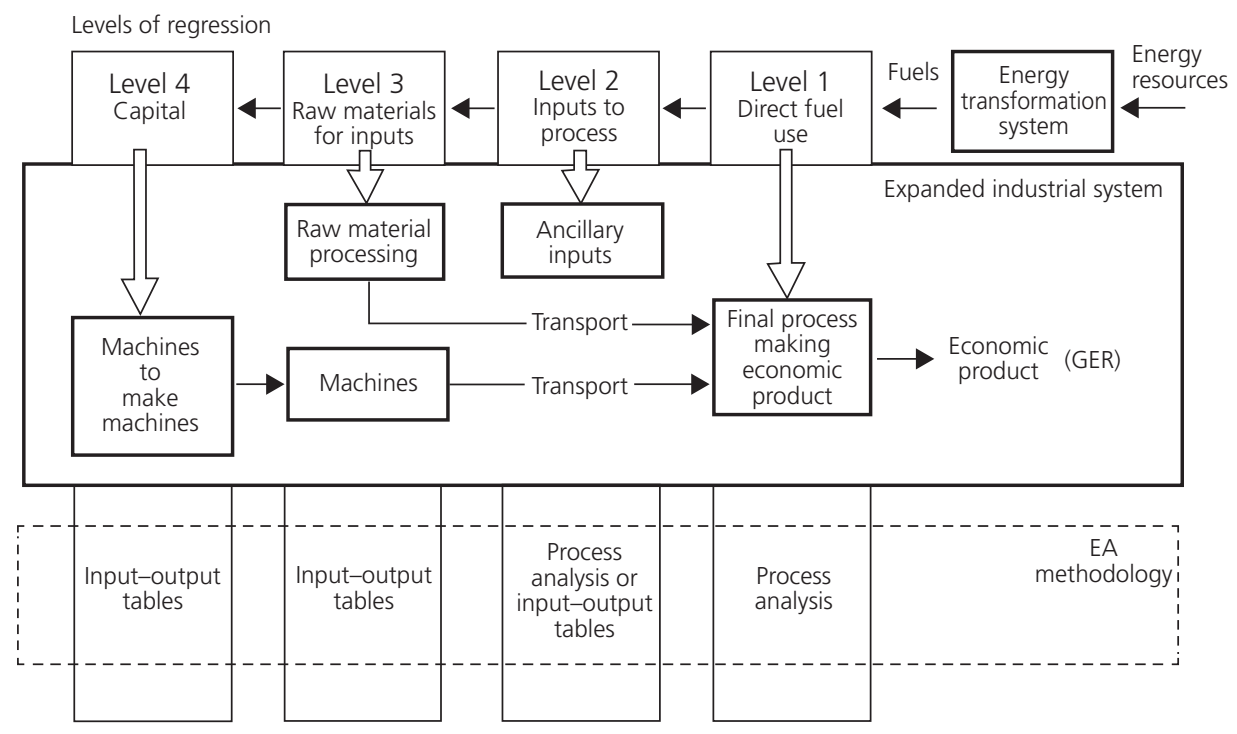

Figure 3. Schematic representation of the EA process (source: Allen et al. (2008); adapted from Slesser (1978)) 


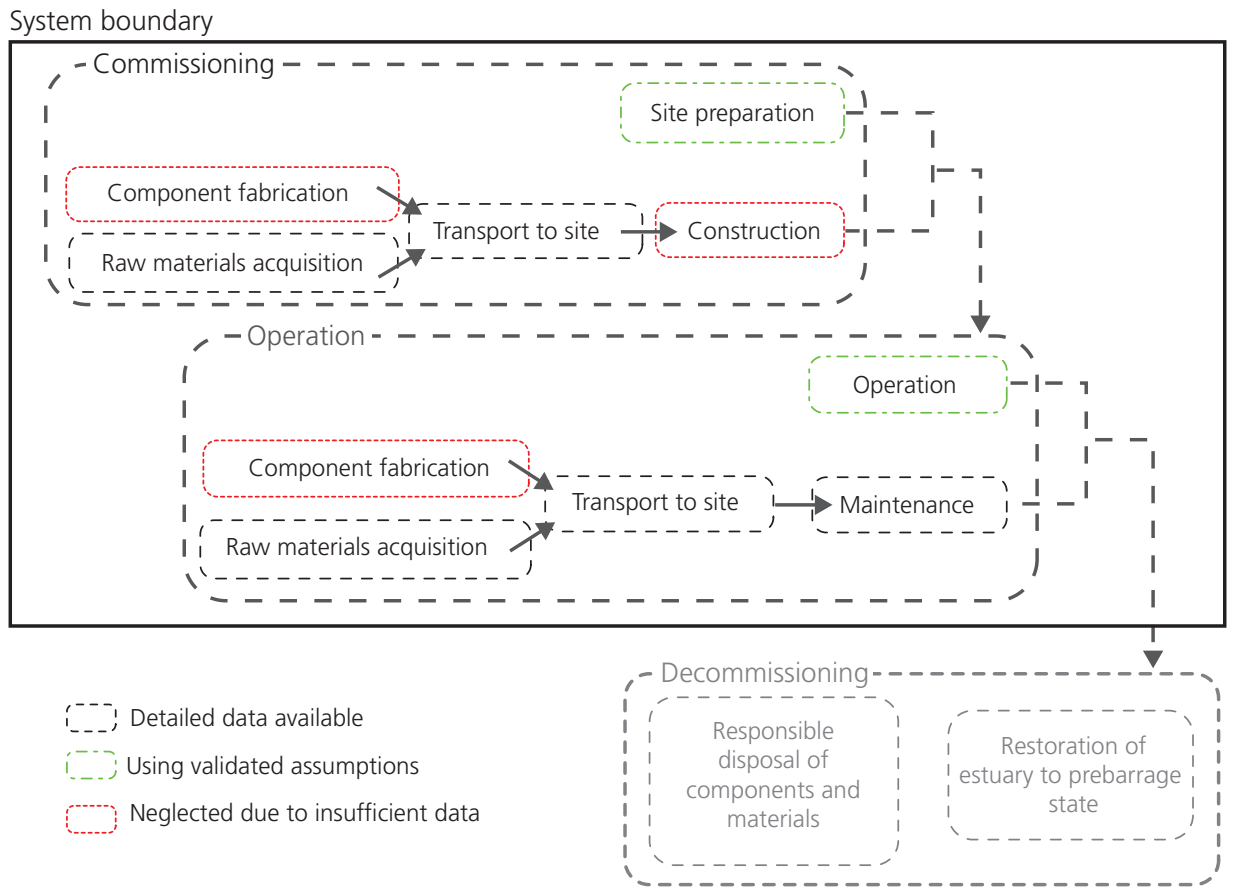

Figure 4. System boundary for tidal power EA and carbon dioxide accounting (source: Hammond et al. (2014))

fabrication of items such as the turbine generators and the caissons. No accurate data were available to account for the direct energy required to manufacture the hydroturbines. Nevertheless, the raw materials required in the manufacture of the turbine (which accounts for the bulk of the associated energy requirements) and the transportation from the manufacturer to the barrage site were estimated. Typically, they reflect the large majority of the embodied carbon dioxide in such a scheme. Likewise, no data existed for the energy required to fabricate items such as the ship locks, and this was again excluded from the EA.

\subsection{Calculation of the energy gain ratio (EGR)}

The EGR divides the useful energy produced by the barrage over its lifespan by the total energy consumed from cradle to grave (Slesser, 1978). The net energy produced is the total net electricity generation - converted from watt-hours to joules for consistency (Cheng and Hammond, 2016; White and Kulcinski, 2000)

$$
\text { 1. } \mathrm{EGR}=\frac{E_{\mathrm{n}, \mathrm{L}}}{E_{\mathrm{mat}, \mathrm{L}}+E_{\mathrm{con}, \mathrm{L}}+E_{\mathrm{op}, \mathrm{L}}+E_{\mathrm{dec}, \mathrm{L}}}
$$

where $E_{\mathrm{n}, \mathrm{L}}$ is the net energy produced over the lifetime of the barrage, $E_{\mathrm{mat}, \mathrm{L}}$ is the total energy invested in materials, $E_{\mathrm{con}, \mathrm{L}}$ is the total energy invested in construction, $E_{\mathrm{op}, \mathrm{L}}$ is the energy required to operate the plant over its lifetime and $E_{\mathrm{dec}, \mathrm{L}}$ is the energy required to decommission the barrage at the end of its life.
The energy required to decommission the barrage (the grave) is outside the system boundary for this EA (see Figure 4). This is in line with all earlier studies of the Cardiff-Weston barrage schemes (DECC, 2008; DECC et al., 2010a; SDC, 2007). It has only been possible to examine partially the energy required to construct the barrage, because of the rough estimates available at the concept design stage of the proposal.

\subsection{Calculation of the energy payback period (EPP)}

The EPP represents the period (the number of years) that a renewable energy (RE) device must operate before it has captured and delivered as much primary energy as has been used to construct the RE technology (Roberts, 1978; Slesser, 1978). The values calculated here were obtained on the basis of a 'static' EA approach (Slesser, 1978). The number of years at which the electricity generated by the barrage equals the primary energy invested in the barrage is therefore known as the EPP.

\subsection{Opportunity cost convention}

In the discipline of economics, the notion of 'opportunity cost' relates the financial opportunity or return that is foregone when an investment is made in one project (the opportunity) in contrast to an alternative (Roberts, 1978). Thus, the equivalent convention in EA concerns the energy foregone to provide energy through another conversion process. In the power sector, fossil fuels (thermal or primary energy) are typically invested in constructing conventional plants rather than in low-carbon dioxide alternatives, such as nuclear power or various RE technologies. In the tidal power case, the opportunity cost (or 'opportunity energy 
A technology assessment of the proposed Cardiff-Weston tidal barrage,

UK

Hammond, Jones and Spevack requirement') will therefore represent the primary energy foregone during the construction of a barrage that is required to generate electricity over its lifetime (Roberts, 1978; Slesser, 1978). To calculate the opportunity cost (OC) in the present study, the weighted average efficiency of the electricity sector $(\eta)$ was taken as $38.5 \%$ (see, for example, Hammond (2000)). The OC equivalent of the standard EGR and EPP mentioned earlier is then obtained by ( $a$ ) dividing the former by $\eta$ and $(b)$ by multiplying the latter by $\eta$ and adding the initial construction period (years).

\subsection{Assumptions and approximations}

\subsubsection{Construction materials: gate to site}

The cradle-to-site energy requirements include the raw material extraction, processing and transportation to the construction site (Hammond and Jones, 2008). These reflect the embodied energy associated with these activities - that is, the total primary energy consumed from direct and indirect processes associated with power production and within the defined cradle-to-site boundary as indicated in Figure 4. In the present analysis, the transportation was examined separately on such a basis. Thus, information relating to the quantity of each raw material required in construction was taken from the report compiled by Black \& Veatch (a global engineering, consulting and construction company) for the SDC (2007). The latest version of the University of Bath's ICE database (v2.0) (Hammond and Jones, 2011b) was then used to determine the embodied energy relating to the raw materials. This database provides a range of embodied energy figures associated with material components, along with an indication of the prevailing scatter in the data. WoollcombeAdams et al. (2009) estimated the carbon dioxide emissions for the Cardiff-Weston barrage tidal barrage scheme across the Severn estuary. They assumed the distances that raw materials would have to be transported and these, combined with the mass of the material, determined the total carbon dioxide emissions. However, the basis for these travel distances was unclear. Therefore, to determine transport distances for the present study, suitable quarries or manufacturers in closest proximity to the barrage site were identified. Having located these sources and the quantities of raw materials required, the primary energy consumption was calculated using data taken from a report by the Institut fur Energie und Umweltforschung (IFEU, 2008). This IFEU report provides coefficients relating the primary energy consumption of various modes of transport to the weight of the material transported and the distance travelled.

\subsubsection{Construction}

Little information is available relating to the exact work requirements to construct the barrage. A decision was therefore made to neglect the construction of components, such as the turbine generator and caissons, in this study. This amounts to an EA that is terminated at level 3 regression, as indicated in Figure 3. However, data for other items (such as dredging and the towing energy) were accounted for here. Roberts (1982) provided information on caisson building for various large tidal barrages. It has been assumed for current purposes that each casting yard consumed $1.75 \times 10^{6} \mathrm{GJ}$ during construction.

\subsubsection{Dredging}

To calculate the energy consumed by dredging, the estimates used by Roberts (1982) were again adopted to determine the energy required to extract rock $\left(\sim 7200000 \mathrm{~m}^{3}\right)$ and sand $\left(\sim 10800000 \mathrm{~m}^{3}\right)$ from a quarry. This value has been verified by comparison with the data in the ICE database (v2.0) (Hammond and Jones, 2011b). In the case of the Cardiff-Weston scheme, the embodied energy through dredging the site is slightly higher than that given by extracting the materials from a quarry.

\subsubsection{Towing energy}

Roberts (1982) assumed that what he termed as 'towing-out' operations gave rise to energy consumption of $54 \times 10^{6} \mathrm{MJ} /$ caisson. This figure has been compared to the energy consumed to transport each caisson a distance of $100 \mathrm{~km}$, to represent an approximate distance between a barrage and fabrication yard. Here the EcoTransIt database (IFEU, 2008) was used to estimate towing for the purposes of EA. In the Cardiff-Weston barrage it was anticipated (DECC, 2008) that four caisson construction yards would be located in the area surrounding the Severn estuary, with another modified existing yard remote from the Severn estuary probably in Scotland. The float-out weights of the Cardiff-Weston caissons were each estimated to be $126000 \mathrm{t}$ (SDC, 2007) for the heaviest of the caissons. This suggests that the towing energy would have a value of about $9 \cdot 1 \times 10^{6} \mathrm{MJ} /$ caisson. Thus, the data provided by Roberts (1982) earlier appear to be pessimistic. To account for the towing energy required to install the ship locks, the segments of the locks were approximated to the same float-out weight as the caissons. The Cardiff-Weston ship lock comprised 14 segments (12 for the 'main lock', two for the 'small craft lock').

\subsubsection{Operation and maintenance allowances}

Roberts (1982) adopted a value for the energy intensity that was equivalent to $5 \cdot 28 \mathrm{MJ} / £$ (2010) to account for the annual operational cost of the barrage. This represents about $1 \cdot 75 \%$ of the total capital cost, in accordance with data more recently provided in the Parsons Brinckerhoff/Black \& Veatch options analysis report for DECC (2008) on the development of tidal power in the Severn estuary. A similar share of the total embodied energy from construction/year of operation was adopted for the present EA. Maintenance was assumed to be required every 40 years; hence, there would be two 5-year maintenance periods for the Cardiff-Weston scheme over its total envisaged lifespan of 120 years. An assumption was made that $70 \%$ of embodied energy related to the manufacture of hydroturbines and their transport and installation (in line with the financial analyses published by DECC (2008), where they made an allowance of $70 \%$ for the M\&E equipment costs). This resulted in operation and maintenance $(\mathrm{O} \& \mathrm{M})$ energy requirements of $15 \cdot 1 \times 10^{6} \mathrm{GJ}$ over the 120 -year projected lifespan for the Cardiff-Weston tidal barrage.

\section{Carbon dioxide accounting}

\subsection{Methodology}

It is widely recognised that to evaluate the environmental impacts of a product or activity, each stage of its life cycle must be considered 
(Hammond and Winnett, 2006). This has led to the development of a range of analytical techniques that now come under the 'umbrella' of environmental life-cycle assessment (LCA). One of the antecedents of this approach was EA of the type described earlier. In a full LCA study, the energy and materials used and pollutants or wastes released into the environment as a consequence of a product or activity are quantified over the whole life cycle, from cradle to grave (Hammond et al., 2015; Heijungs et al., 1992; Udo de Haes and Heijungs, 2007). The methodology of LCA follows closely that developed for EA (Allen et al., 2008; Hammond and Winnett, 2006; Hammond et al., 2013, 2015; Slesser, 1978), but evaluates all the environmental burdens associated with a product or process over its whole life cycle. This requires the determination of a balance or budget for the raw materials and pollutant emissions (outputs) emanating from the system. Energy is treated concurrently, thereby obviating the need for a separate EA (Hammond and Winnett, 2006). LCA is often geographically diverse - that is, the material inputs to a product may be drawn from any continent or geopolitical region of the world (Hammond and Jones, 2008). But, as previously argued, carbon dioxide footprints have become the 'currency' of debate in a climate-constrained world. Consequently, the emphasis in the present study was on carbon dioxide emissions, rather than the wider set of environmental burdens (Allen et al., 2008; El-Fadel et al., 2010; Hammond et al., 2012, 2013; Woollcombe-Adams et al., 2009). An emissions coefficient (in grams carbon dioxide per kilowatt-hour of electricity $\left(\mathrm{kWh}_{\mathrm{e}}\right)$ ) for the Cardiff-Weston barrage scheme was calculated using an expression derived by White and Kulcinski (2000)

$\frac{\mathrm{kg} \text { carbon dioxide }}{\mathrm{kWh}}=\frac{\sum_{i}\left(\mathrm{~kg} \text { carbon dioxide } / \mathrm{kg} \mathrm{M}_{i}\right) \mathrm{kg} \mathrm{\textrm {M } _ { i }}}{E_{\mathrm{n}, \mathrm{L}}}$

2.

where $E_{\mathrm{n}, \mathrm{L}}$ is the net electrical energy produced over the lifetime of the barrage; $\mathrm{kg}$ carbon dioxide $/ \mathrm{kg} \mathrm{M}_{i}$ is the kilograms of carbon dioxide emitted per kilogram of material $i$ produced; and $\mathrm{kg} \mathrm{M}_{i}$ is the quantity of material $i$ needed to construct and/or operate the barrage. Similar methods were used for carbon dioxide analysis as those employed to calculate the embodied energy (Hammond and Jones, 2008) and other primary energy requirements.

\subsection{Assumptions and approximations}

To calculate the cradle-to-site carbon dioxide equivalent emissions, an approach was taken that was similar to that employed for the EA described earlier (see also Figure 4). The University of Bath's ICE database (v2.0) (Hammond and Jones, 2011b) was again used to determine the cradle-to-gate carbon dioxide emissions associated with raw materials. The gate-to-site emissions were then calculated per tonne of material per kilometre travelled. However, the energy consumed to construct the Cardiff-Weston barrage has been neglected, due to the lack of available data. No specific data exist relating to the carbon dioxide emissions generated during dredging. The emissions released to quarry the materials were therefore extracted again from the ICE database (Hammond and Jones, 2008, 2011b). Carbon dioxide emissions during towing out have been ignored, due again to insufficient data being available. The method used for the EA (employing the EcoTransIt database (IFEU, 2008)) did not adequately represent the towing-out energy for the caissons and hence cannot reliably be used to estimate carbon dioxide emissions. The carbon dioxide emissions generated during the annual operation of the Cardiff-Weston barrage, as well as the maintenance periods every 40 years, were estimated by adopting the same approximations as described for the EA earlier. Maintenance has been equated to $70 \%$ of the total M\&E equipment carbon dioxide emissions, producing values of $0.97 \times 10^{6} \mathrm{t}$ carbon dioxide for the Cardiff-Weston barrage. Annual operational carbon dioxide emissions were taken as $1.75 \%$ of the total emissions released during construction; this converts to $12 \times 10^{6} \mathrm{t}$ carbon dioxide for the Cardiff-Weston scheme based on a 120-year lifespan. But carbon dioxide emissions released during the projected decommissioning phase were again not accounted for.

\section{Financial investment appraisal}

\subsection{Background}

Economic appraisal evaluates the costs and benefits of any project, programme or technology in terms of outlays and receipts accrued by a private entity (household, firm etc.) as measured through market prices (Brent, 1996). Financial appraisal is used by the private sector and omits so-called environmental externalities. In contrast, economic CBA is applied to take a society-wide perspective, with a wholesystems view of the costs and benefits (Allen et al., 2008; Hammond and Winnett, 2006). It accounts for private and social, direct and indirect, tangible and intangible elements, regardless of to whom they accrue and whether or not they are accounted for in purely financial terms (Brent, 1996). Allen et al. (2008) applied both financial appraisal and CBA to evaluate a number of microgenerators, whereas Hammond et al. (2012) more recently used them to evaluate a building-integrated solar photovoltaic (PV) array. A further distinction between financial appraisal and CBA is in the use of the discount rate to value benefits and costs occurring in the future (Allen et al., 2008; Hammond and Winnett, 2006; Hammond et al., 2012). Financial appraisal uses the market rate of interest (net of inflation) as a lower bound and therefore indicates the real return that would be earned on a private sector investment.

\subsection{Capital expenditure and the breakdown of annual costs}

The capital expenditure associated with a Severn estuary tidal barrage project was taken from a study sponsored by DECC (2008). It provided detailed cost estimates for the Cardiff-Weston scheme in terms of construction, electricity generation and operational costs. The STPG (1989) report described a capital cost breakdown over a 6 -year preconstruction period. This was compressed here to fit the construction period of 5 years envisaged by DECC (2008). The maintenance costs were again approximated at $70 \%$ of the $M \& E$ generating plant every 40 years, with two maintenance periods of 5 years each. The annual operation cost of the barrage was taken as $1 \cdot 75 \%$ of the total construction cost for the scheme. This is 
generally in line with the estimates made by DECC (2008), although they state that in the case of the Cardiff-Weston barrage, they estimated an annual cost of just $1 \cdot 25 \%$. However, the SDC (2007) felt that 'short-termism' in the barrage design could lead to unsustainable ancillary developments and possibly suboptimal methods or materials being used in its construction.

\subsection{Compensation for habitat loss}

An additional, or 'compensatory', allowance for habitat loss has been included only in the most recent studies. This allows for possible compensatory measures under article 6(4) of the EU habitats directive (EC, 2007). The Cardiff-Weston scheme would potentially have a significant impact on the Severn estuary (whose geography is illustrated in Figure 1). The potential need for compensation for a salt marsh depends on whether this is based on the loss of salt marsh immediately following construction of a scheme, or the 'net change' taking account of predicted losses or gains in habitat (DECC et al., 2010b). Compensation ratios of between $1: 1$ and $3: 1$ could be applied for up to 690 ha of salt marsh habitat creation. The compensatory habitat costs for this tidal barrage might then range from $£ 1.33$ billion to $£ 3.94$ billion. Depending on how the total scheme would be funded, the compensatory allowance for the Cardiff-Weston scheme could be provided by the private sector.

\subsection{Discounted cash flow investment appraisal}

This approach takes account of the 'time value of money' and discounts to obtain the appropriate investment appraisal criteria (Allen et al., 2008; Hammond and Winnett, 2006; Kohyama, 2006). The levelised unit electricity cost (LUEC) is typically employed to compare the economic performance of different power generators. This is the price at which electricity must be sold to recover all costs incurred during generation. The net present value (NPV) of the sum of the capital cost, maintenance and operational costs and, potentially, decommissioning is calculated over the life of the project, along with the NPV of the total electricity generated. This yields the LUEC in pence per kilowatt-hour ( $\mathrm{p} / \mathrm{kWh}$ ) for the Cardiff-Weston barrage, which can then be compared to that for alternative power generators. Consequently, by using this method, different energy options with a variety of lifespans, capital costs and efficiencies can effectively be compared so that the most cost-effective option can be determined. The discounted cash flow (DCF) over the life of each project - here assumed to be 120 years for the Cardiff-Weston barrage - is calculated as follows

$$
\text { 3. } \mathrm{DCF}=\sum_{t=1}^{t=120} \frac{R_{t}}{(1+\mathrm{TDR})^{t}}
$$

where $R_{t}$ is the net receipts (income less cost), $t$ is the time in years for the total foreseen life of the project and TDR is the so-called Test Discount Rate, typically utilised in the case of public sector (or 'social') investments. It is derived from a comparison with private sector discount rates (or weighted average cost of capital (WACC)). In the UK, HM Treasury (2003) recommends that the TDR for projects with durations of less than 30 years should be taken as $3 \cdot 5 \%$, then falling in line with the profile indicated in Table 3.

The results obtained by DECC (2008) do not use these TDR values, as they believe that it would not satisfactorily manage all of the risks associated with such a project and will represent only the case of the scheme being entirely funded through the public sector (DTI, 2007). The LUEC values presented by the DECC (2008) employed a discount rate of $8 \%$, which they regard as reflecting the WACC that would enable the project to be financed by the private sector.

\section{Results and discussion}

\subsection{Energy analysis}

\subsubsection{Cradle-to-site analysis}

Embodied energy associated with the material requirements for the Cardiff-Weston tidal barrage were obtained from the ICE database (Hammond and Jones, 2008, 2011b). The largest contributors in terms of the energy requirements for the scheme (see Figure 5) were associated with cement (28\%) and the hydroturbines $(22 \%)$. This contrasts with the Shoots barrage (Hammond et al., 2014), for which 58\% of the embodied energy was related to limestone rock, assumed to be quarried and then shipped from the Glensanda superquarry in Scotland.

\subsubsection{Total energy requirements}

Energy requirements for commissioning and operation of the Cardiff-Weston and Shoots barrages are compared and contrasted in Figure 6. The major element of the total energy consumed was found to arise due to the operational energy requirements of the barrage. This suggests that the assumptions made about the commissioning of the scheme have a relatively minor influence on the overall energy requirements. The energy required to fabricate the individual components and the barrage itself was therefore neglected in the present study.

\subsubsection{Energy gain ratio (EGR)}

Table 4 displays the EGR calculated using assumptions outlined earlier. The final energy gain ratios have been put into context by comparing them to other electricity generation plants. It has been possible to recalculate the EGR values for conventional nuclear and coal power plants so that they do not include plant construction or decommissioning energy requirements. These figures can then be more easily compared to the present ones (in Table 4). The EGR for the Cardiff-Weston tidal barrage is approximately double that of the coal plant investigated by White

Table 3. The declining long-term UK test discount rate

$\begin{array}{lccc}\text { Period of years } & 0-30 & 31-75 & 76-125 \\ \text { Discount rate: } \% & 3.5 & 3.0 & 2.5\end{array}$

Source: HM Treasury (2003) 
Engineering Sustainability

Volume 171 Issue ES8
A technology assessment of the

proposed Cardiff-Weston tidal barrage,

UK

Hammond, Jones and Spevack

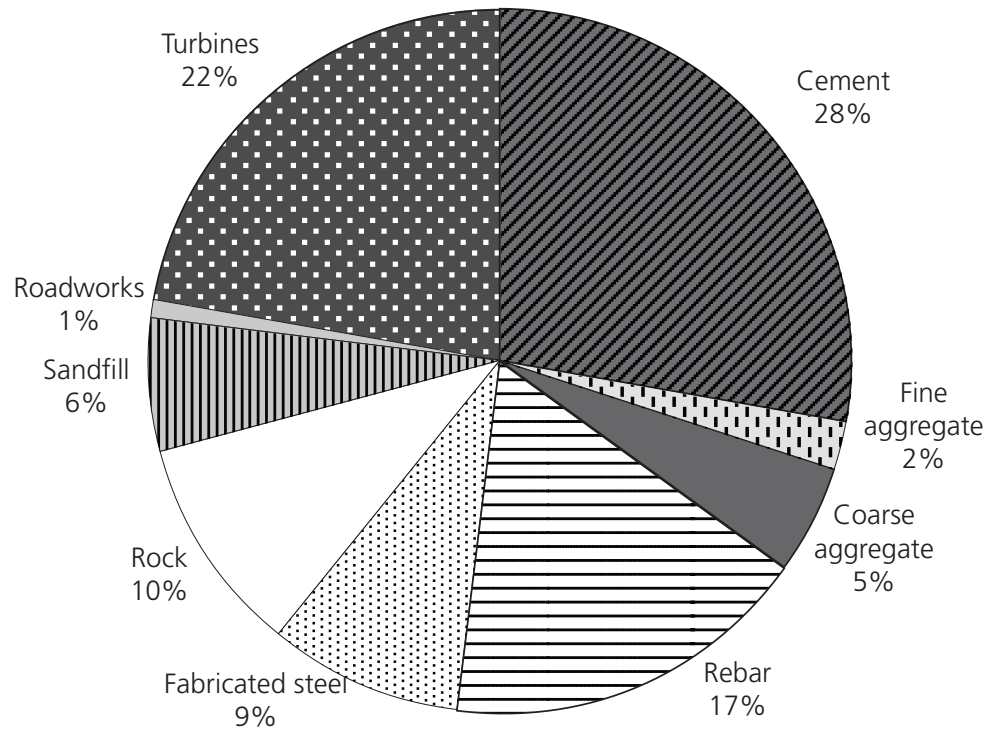

Figure 5. Cradle-to-site EA: embodied energy resulting from material inputs to the Cardiff-Weston tidal power barrage

and Kulcinski (2000). So the Cardiff-Weston tidal power scheme gives rise to an EGR slightly better (i.e. larger) than those of nuclear (fission) power stations. The EGR for wind, despite taking into account the energy consumed during construction and decommissioning, is higher than those of the Cardiff-Weston barrage. An average value has been taken for the results of the earlier mentioned cradle-to-site analysis, and the EGR values were calculated at three different possible lifespans - from a full lifespan of 120 years down to 40 years (which is slightly less than the 44-year lifespan of the La Rance barrage (located on the estuary of the Rance River in Brittany, France), the longest

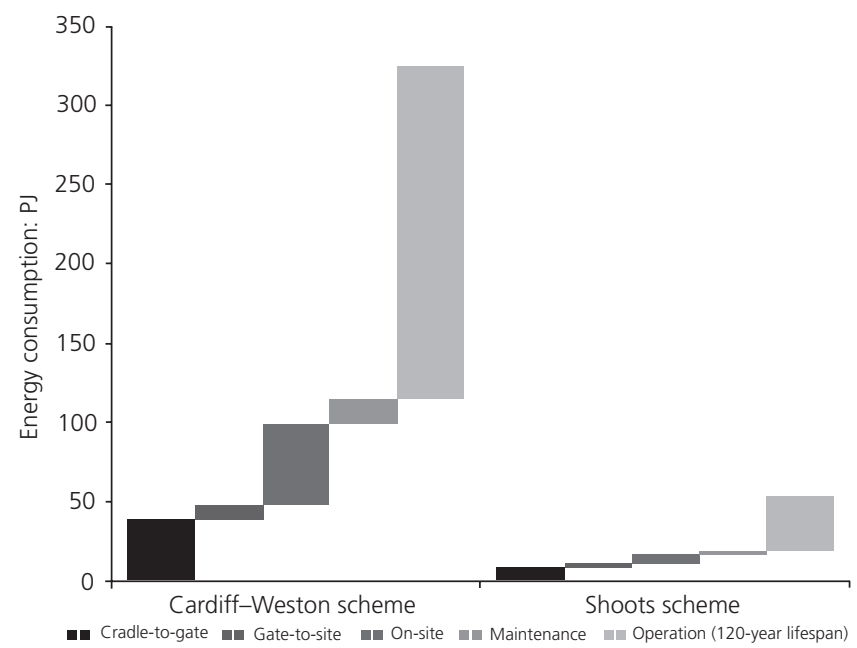

Figure 6. Comparison of the total energy requirements for commissioning and operating the Cardiff-Weston and Shoots tidal barrages over their 120-year lifespans (data for the Shoots barrage have been taken from the study reported by Hammond et al. (2014)) proven lifespan for this technology to date). The Cardiff-Weston barrage EGR fell from $22 \cdot 2$ over a 120 -year lifespan to $19 \cdot 4$ for an 80 -year life and to $14 \cdot 0$ for one of 40 years.

\subsubsection{Opportunity cost convention}

This convention was applied to the EGR estimated above for a 120 -year (default) lifespan. The EGR for the Cardiff-Weston tidal barrage then rose from $22 \cdot 2: 1$ to $57 \cdot 6: 1$. In terms of energy, this obviously makes this scheme a highly attractive power generation option on a like-for-like basis.

\subsubsection{Energy payback period (EPP)}

The EPP indicates the time taken, in months following first operation, for the amount of energy generated by the Cardiff-Weston barrage to equal the energy consumed during commissioning and operation up to that moment in time. It should again be noted that not all of the energy consumed during this phase could be accounted for in this study; hence, it should be assumed that the current figures are optimistic. The EPP for the Cardiff-Weston tidal power scheme is 31 months from first

Table 4. Estimated energy gain ratios (EGR) for alternative power generators

\begin{tabular}{|lcc|}
\hline Scheme & EGR & Lifespan: years \\
\hline Cardiff-Weston tidal barrage & $22 \cdot 2$ & 120 \\
Coal-fired power plant & $10 \cdot 8\left(10 \cdot 3^{*}\right)$ & 40 \\
Nuclear power station & $17 \cdot 8\left(16 \cdot 4^{*}\right)$ & 40 \\
Wind turbine (without storage) & $\left(23^{*}\right)$ & 25
\end{tabular}

Data for alternative power generators taken from White and Kulcinski (2000). Numbers with an asterisk $\left(^{*}\right)$ indicate EGR values with the inclusion of plant construction and decommissioning. Energy use associated with decommissioning and waste disposal from coal-fired plant was found to be negligibly small, although that for plant materials and construction (5\%) not quite so 
A technology assessment of the

proposed Cardiff-Weston tidal barrage,

UK

Hammond, Jones and Spevack commissioning, assuming just a $50 \%$ power generation capacity in year 1. Taking a construction period of 6 years, this equates to a total energy payback of 8.6 years. This is slightly shorter than that of the much smaller Shoots barrage (Hammond et al., 2014), but this difference is not significant over a lifespan of 120 years. By applying opportunity cost convention, the EPP for the Cardiff-Weston barrage was only $7 \cdot 0$ years, which indicates a strong case (in energy terms) for the implementation of such a scheme.

\subsection{Carbon dioxide accounting}

\subsubsection{Cradle-to-site emissions}

Two earlier cradle-to-gate studies of the carbon dioxide emissions were previously completed by the SDC (2007) and by Woollcombe-Adams et al. (2009); the data obtained during the present study were compared to those from these two previous sources. These employed an embodied energy value for rock that was slightly higher than that adopted here, but the material type was confirmed by a member of the Severn barrage steering committee. The carbon dioxide coefficient for extracting the material from the quarry adopted for the present study was taken from a more recent version from the ICE database (v2.0) (Hammond and Jones, 2011b). Thus, the main contributors to embodied carbon dioxide equivalent emissions associated with the Cardiff-Weston barrage come from cement $(\sim 2 \cdot 0$ million tonnes carbon dioxide equivalent $\left.\left(\mathrm{MtCO}_{2} \mathrm{e}\right)\right)$, rock $\left(\sim 1 \cdot 2 \mathrm{MtCO}_{2} \mathrm{e}\right)$ and steel $\left(\sim 0.5 \mathrm{MtCO}_{2} \mathrm{e}\right.$, plus $\sim 0.3 \mathrm{MtCO}_{2} \mathrm{e}$ of rebar and $\sim 0 \cdot 25 \mathrm{MtCO}_{2} \mathrm{e}$ of fabricated steel). Cement is the primary ingredient in concrete, and its production releases GHGs both directly and indirectly. Direct emissions arise from the heating of limestone that releases carbon dioxide directly, while fossil fuel combustion in the kiln also indirectly results in carbon dioxideequivalent emissions. The extraction of the required quantities of cement makes it the largest contributor to the embodied carbon dioxide of this barrage. Only the SDC (2007) study - undertaken for them by Black \& Veatch - published detailed results, and these do not compare well with those from the present study. Variances are likely to be mainly due to different assumptions about the material content of the barrage and to a lesser extent to the fact that Black \& Veatch used an older version of the ICE database (v1.5).

\subsubsection{Total carbon dioxide emissions}

The highest carbon dioxide-equivalent emissions occur during the operational phase of the Cardiff-Weston barrage (around two-thirds); see Figure 7. This is analogous to the total energy requirement (Figure 6). The assumption of $1.75 \%$ of the total emissions during construction has been taken from the financial model first employed by DECC (2008). It is far higher than in the earlier report by the STPG (1986). However, the proportion of 'onsite' carbon dioxide emissions is smaller than that found in the EA presented earlier. This was in part due to items, such as towing energy requirements, being ignored in the present analysis. The total carbon dioxide emissions over the assumed 120-year lifespan were some 20.0 and $2 \cdot 75 \mathrm{Mt}$ carbon dioxide for the Cardiff-Weston and Shoots tidal power schemes, respectively (see again Figure 7).

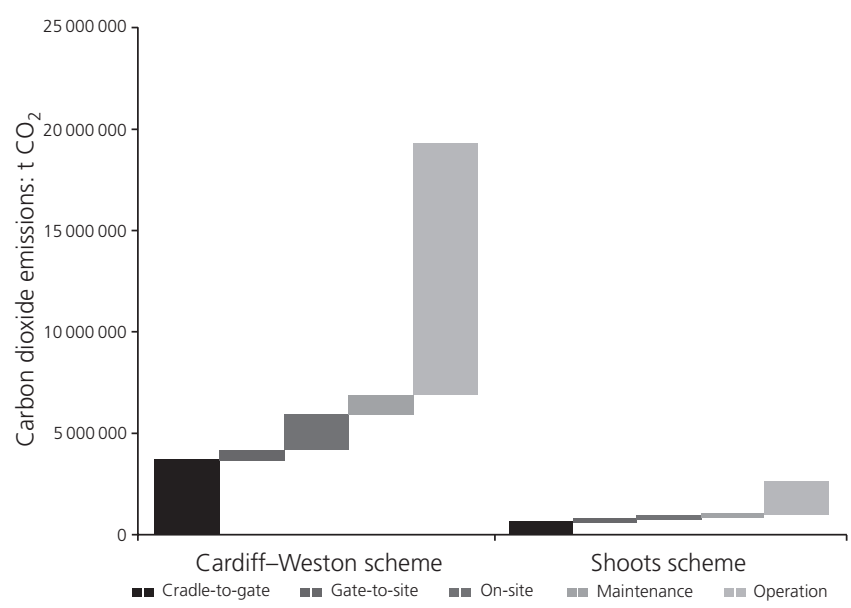

Figure 7. Comparison of carbon dioxide emissions emanating from the commissioning and operation of the Cardiff-Weston and Shoots tidal barrages over their 120-year lifespans (data for the Shoots barrage have been taken from the study reported by Hammond et al. (2014))

\subsubsection{Carbon dioxide emissions per unit of electricity}

Estimates of the carbon dioxide emissions per unit of electricity generated (in $\mathrm{g}$ carbon dioxide/ $\mathrm{kWh}$ ), sometimes referred to as the carbon dioxide ratio or 'carbon ratio' (Hammond, 2000) were made assuming a lifespan of 120 years. The range of carbon dioxide emissions was calculated by applying the data spread obtained at the cradle-to-gate phase. The overall results show that the Cardiff-Weston tidal barrage would emit 9.5-11.0 grams carbon dioxide equivalent $\left(\mathrm{gCO}_{2} \mathrm{e}\right) / \mathrm{kWh}_{\mathrm{e}}$. This contrasts with the value associated with the Shoots barrage scheme, which would emit about 6.7-8.7 $\mathrm{gCO}_{2} \mathrm{e} / \mathrm{kWh}_{\mathrm{e}}$ (Hammond et al., 2014). Work sponsored under the auspices of the IPCC (Moomaw et al., 2011) indicates the carbon dioxide intensity of alternative power generators: coal (without carbon dioxide capture and storage $(\mathrm{CCS})) \sim 1000 \mathrm{~g}$ carbon dioxide $/ \mathrm{kWh}_{\mathrm{e}}$; combined cycle gas turbines (CCGTs; without CCS) - $443 \mathrm{~g}$ carbon dioxide/ $\mathrm{kWh}_{\mathrm{e}}$; nuclear - $66 \mathrm{~g}$ carbon dioxide $/ \mathrm{kWh}_{\mathrm{e}}$; solar PV - $32 \mathrm{~g}$ carbon dioxide $/ \mathrm{kWh}_{\mathrm{e}}$; and onshore wind $-10 \mathrm{~g}$ carbon dioxide $/ \mathrm{kWh}_{\mathrm{e}}$. These clearly suggest that tidal power schemes exhibit attractive 'figures of merit' in terms of a low level of carbon dioxide emissions. But it should be noted that not all of the sources of emissions could be accounted here, and the actual results would consequently be slightly higher in reality.

\subsection{Financial investment appraisal}

\subsubsection{Baseline LUEC}

This analysis provides a 'baseline cost' (or levelised unit electricity cost (LUEC)) for the Cardiff-Weston tidal power barrage of $14.0 \mathrm{p} / \mathrm{kWh}$. It was obtained using the DECC (2008) DCF investment appraisal approach with constant capital expenditure over the preconstruction and the 6-year construction periods (see Table 5, which includes the most likely 'best' and 'worst' cases in this tidal barrage scheme) by using the declining test discount rate 
Engineering Sustainability

Volume 171 Issue ES8
A technology assessment of the

proposed Cardiff-Weston tidal barrage,

UK

Hammond, Jones and Spevack
Table 5. Estimated levelised unit electricity cost (LUEC) values of the proposed Cardiff-Weston tidal barrage scheme (under the most likely best and worst cases)

\begin{tabular}{lcc} 
& \multicolumn{2}{c}{$\begin{array}{c}\text { Cardiff-Weston tidal power barrage } \\
\text { (STPG (1989) construction) }\end{array}$} \\
\cline { 2 - 3 } & Best case & Worst case \\
\hline Compensatory habitat & $1: 1$ & $3: 1$ \\
Construction cost & Baseline cost & Plus $5 \%$ \\
Optimism bias: $\%$ & 6 & 40 \\
Operational cost: $\%$ & $1 \cdot 25$ & $2 \cdot 00$ \\
Energy generation & As stated (plus 0\%) & $-10 \%$ \\
Maintenance cost & $70 \%$ M\&E equipment & $100 \%$ M\&E cost \\
& every 40 years & every 40 years \\
Lifetime: years & 120 & 45 \\
LUEC: p/kWh & 13.0 & 21.8
\end{tabular}

(TDR) (see Table 3; advocated by HM Treasury (2003)). The corresponding baseline cost for the Shoots barrage (Hammond et al., 2014) was found to be $10 \cdot 8 \mathrm{p} / \mathrm{kWh}$. These are slightly higher than those using the more detailed breakdown derived from the STPG (1986), although this does not represent a significant difference. Here the ultimate LUEC variation over a 120 -year lifespan of the Cardiff-Weston barrage as determined through the DECC (2008) study was based on whether or not compensatory habitat (see Section 5.3) is required. The highest value was $21 \cdot 8 \mathrm{p} / \mathrm{kWh}$ for a $3: 1$ compensatory habitat, while the lowest figure was $13 \cdot 0 \mathrm{p} / \mathrm{kWh}$ for a $1: 1$ compensatory habitat. STPG (1989) employed a model of the capital expenditure over a 6-year period to investigate how the test discount rate influences the LUEC. This range, assuming a 120-year lifespan, varied according to the TDR applied: $28.9 \mathrm{p} / \mathrm{kWh}$ for a $15 \% \mathrm{TDR}, 13.3 \mathrm{p} / \mathrm{kWh}$ for an $8 \% \mathrm{TDR}$ and just $3 \cdot 2 \mathrm{p} / \mathrm{kWh}$ for a zero discount rate. The $8 \%$ TDR figure may be regarded as a 'baseline figure' as it presents the most likely price of the electricity produced. In contrast, the DECC (2008) study by the consultants Black \& Veatch of the Cardiff-Weston barrage suggested an LUEC figure of $3.3 \mathrm{p} / \mathrm{kWh}_{\mathrm{e}}$ for a social discount rate of $3 \cdot 5 \%$, or $6 \cdot 8 \mathrm{p} / \mathrm{kWh}$ for an investor discount rate of $8 \%$ over the 120 -year lifespan.

DECC (2008) published a range of LUEC values based on whether or not compensatory habitat is required; these have been compared to the present best-to-worst range for the Cardiff-Weston barrage in Figure 8. In the Cardiff-Weston case, the highest value from the DECC study of $15 \cdot 29 \mathrm{p} / \mathrm{kWh}$ is based on the provision of $3: 1$ compensatory habitat and the lowest of $13.72 \mathrm{p} / \mathrm{kWh}$ is for $1: 1$; these have been selected to fit with the best- and worst-case figures obtained in this present study in Table 5. In the case of the Shoots barrage, the worst case from the DECC study of $11.49 \mathrm{p} / \mathrm{kWh}$ represents $1: 1$ compensatory habitat and the best case of $10 \cdot 4 \mathrm{p} / \mathrm{kWh}$ is for no compensatory habitat.

\subsubsection{Comparison with alternative power generators}

The economics of the Severn estuary tidal barrage scheme may be compared to that of alternative power generators. This study has confirmed the conclusions of a number of earlier studies (such as

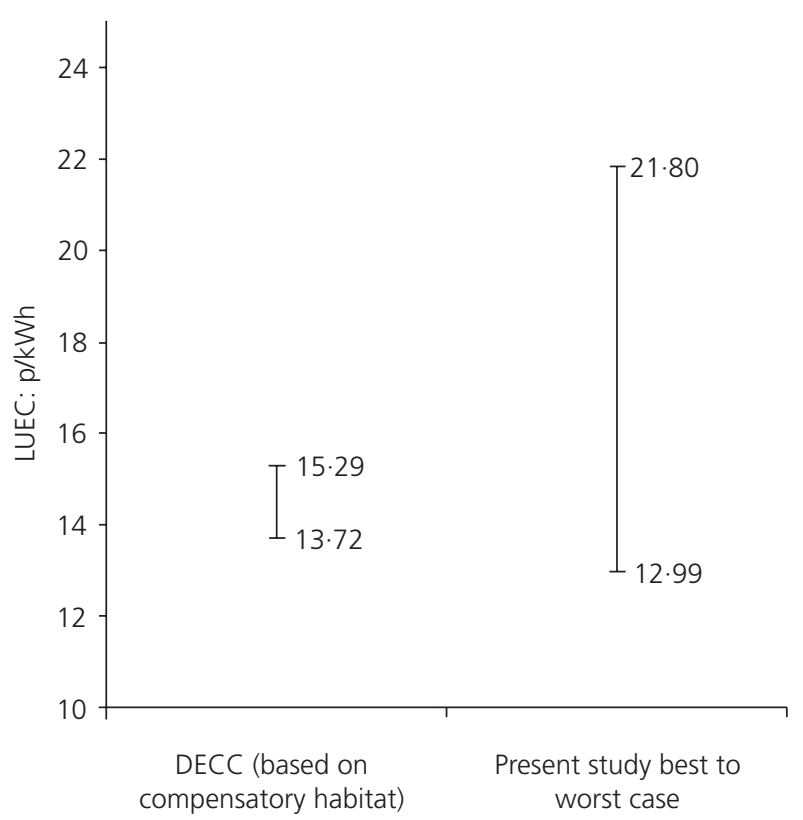

Figure 8. Levelised unit electricity cost (LUEC) range for the Cardiff-Weston tidal barrage (together with the best to worst cases from DECC studies; after Gross et al. (2010))

that by the consulting engineers Mott MacDonald Ltd (2010)) that the electricity generated by tidal power schemes is not commercially attractive in comparison with some of the alternative technologies. The LUEC ranges derived from this present study have been compared to those for alternative power generators in Figure 9, where costs for the latter technologies have been taken from Gross et al. (2010) (extracted from the original report by Heptonstall (2007)). Mott MacDonald Ltd (2010) found, using a discount rate of $10 \%$, the 2010 LUEC for a number of power plant types: gas CCGT $-8.03 \mathrm{p} / \mathrm{kWh}$; coal

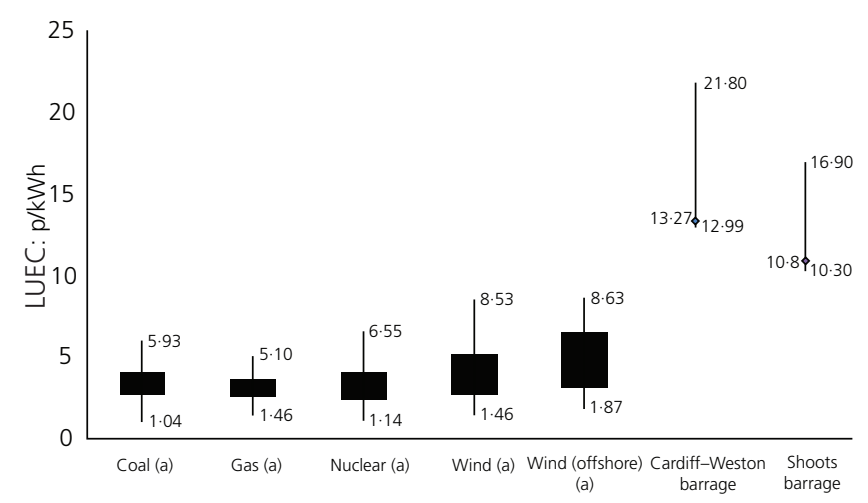

Figure 9. Levelised unit electricity cost (LUEC) ranges for the Cardiff-Weston and Shoots tidal barrages over their 120-year lifespans in comparison to various alternative power generators (source: data for Shoots barrage have been taken from the study reported by Hammond et al. (2014) and those for the alternative electricity generators (a) from Gross et al. (2010)) 
Engineering Sustainability

Volume 171 Issue ES8
A technology assessment of the

proposed Cardiff-Weston tidal barrage,

UK

Hammond, Jones and Spevack (without CCS) - 10.45 p/kWh; nuclear - 9.90 p/kWh; onshore wind $-9.39 \mathrm{p} / \mathrm{kWh}$; and offshore wind $-16.09 \mathrm{p} / \mathrm{kWh}$. However, the impact of the selected TDR was found to be significant. No allowance has been made for the cost of decommissioning the barrage in the present study; this is due to limited data being available, as well as the longevity of the project, and also to keep this study in line with other studies, such as those by DECC (2008) and the STPG (1986).

\section{Ecological and environmental impacts}

Human society is underpinned by energy sources of various kinds that provide heat and power for the everyday life of its citizens. But all energy technologies have unwanted 'side effects'; they simply differ in their level of severity (Hammond, 2000). Many of these side effects give rise to resource uncertainties and potential environmental hazards on local, regional and global scales. Arguably, the principal environmental side effect of energy supply is the prospect of global warming, due to an enhanced greenhouse effect induced by combustion-generated pollutants (IPCC, 2013). It has been shown (in Section 6.2) that the Cardiff-Weston tidal barrage exhibits a low level of carbon dioxide emissions per unit of electricity produced in comparison to some of the alternative power generators, in particular fossil-fuelled plants. Thus, such tidal power schemes can make a useful contribution towards mitigating global warming, the most critical environmental concern in a climate-constrained world (Alderson et al., 2012). They would displace fossil-fuelled power stations that give rise to much higher carbon dioxide emissions. In addition, some have argued that there would be substantial flood risk alleviation benefits from such a barrage (although these are likely to be only marginal to the economic case for its construction). The barrage would provide a flood defence against storm surges, particularly on high spring tides and potentially offer additional communication links between the south-west of England and south Wales. For these sorts of reasons, the former SDC (2007) believed that there was a strong case to be made for a 'sustainable' STP scheme. But, like other energy options, it gives rise to some environmental disbenefits at a more local scale.

The building of the Cardiff-Weston barrage would make significant modifications to the estuarine environment of the River Severn, resulting in the loss of intertidal habitat. However, the Parliamentary Office of Science and Technology (Post, 2013) noted that studies of habitat response have been restricted to the use of conceptual models. Such models focus on the hydrodynamic effects on physical habitats, while the implications for biodiversity and water quality have been largely neglected (a recent exception being the review by Kadiri et al. (2012)). The salinity of the water and dispersal of pollutants is likely to be affected by the barrage construction. Local plant and animal populations, in particular birds who currently feed on the tidal mudflats, are likely to be impacted. Indeed, the types of animals and plants that colonise the estuary may well change (Kirby and Shaw, 2005). Post (2013) observed that, although hydroturbines can be designed to lower fish mortality, it is uncertain whether they would actually maintain fish populations. A barrage would clearly change tidal heights and the behaviour of suspended soil, causing alterations to mudflats and sandbanks. It is contended by Post (2013) that fish stocks will be subject to increased predation, disease and disruption to their movement. In contrast, Kirby and Shaw (2005) believed that the foreshores of the Severn estuary have a very low carrying capacity for birds and yield poor feeding grounds for fish. They suggested that a tidal barrage project would lead to increases in mean water levels and shelter, while current strengths would fall. That would arguably encourage fish colonisation. Post (2013) argued that, whatever the case, there is limited evidence on the efficacy of habitat compensatory and mitigation measures (EC, 2007) for birds, fish and invertebrates.

A number of researchers have attempted to use the La Rance tidal barrage in Brittany (that has been operating for almost 50 years) as a physical analogue of the ecological impacts that might result from the proposed Cardiff-Weston barrage (Binnie, 2016; Hooper and Austen, 2013; Kirby and Retière, 2009). The comparative study by Kirby and Retière (2009) found that there were significant differences in the nature of the two sites, although they suggested that both result in significant rises in biodiversity and abundance of species. Hooper and Austen (2013) observed that the La Rance barrage had increased the mean water height in the basin (by some $2.5 \mathrm{~m}$ ) and decreased the tidal range (by around $40 \%$ ) and the tidal strength had reduced. The intertidal zone was reduced from 70 to $50 \%$ of the total surface area of the basin, along with a slight fall in turbidity levels $(\sim 5 \%)$. These alterations led, in turn, to changes in the erosion of the banks, the relocation of the sandbanks and increases in fine sediments in adjacent caves and bays. Overall, these have resulted in the La Rance barrage having a biological productivity higher than those of similar estuaries. Thus, Hooper and Austen (2013) argued that La Rance is an example that indicates that marine life can successfully adapt to the effects of the development of tidal barrages, although it took a decade after construction for an ecological balance to be restored. Kirby and Retière (2009) asserted from their comparative study that whether the anticipated changes in environmental and water quality would make the Severn estuary better or worse was a question of perception. But Pethick et al. (2009) noted that the La Rance barrage was built before it became common practice to determine the preconstruction habitat baseline for such barriers. Consequently, there is a lack of empirical data on geomorphological and ecological changes due to the insertion of the barrier into the La Rance River estuary. Indeed, the La Rance barrage was constructed by blocking off the estuary above the site from all tidal flows during construction. The estuary above the barrage became a freshwater habitat for the duration of construction. In contrast, the Cardiff-Weston barrage would allow tidal flows to continue above the barrage for the full duration of assembly. It may therefore be argued that the ecological balance will not be totally changed during construction and that comparison between the two schemes might not be valid.

Pethick et al. (2009) observed that the storm surge barrage constructed on the Eastern Schelde in the Netherlands (over the period 1983-1987) behaves like a barrier by allowing the free 
passage of water in a similar manner to an ebb-flood barrage (see also Post (2013)). It may therefore yield a more realistic analogue for the proposed Cardiff-Weston tidal power scheme. The Eastern Schelde barrier has a similar geomorphology, which resulted in a reduced tidal range and changes in the sediment pathway not unlike those expected in the Bristol Channel. Pethick et al. (2009) employed 'expert geomorphological analysis' that raised a number of important concerns regarding the potential construction of the Cardiff-Weston barrage. They noted that much more information is needed on the impact of large-scale sediment circulation and the erosion of foreshores. These may undermine flood defence infrastructures and induce greater wildlife homogeneity, something that is contrary to nature conservation objectives.

\section{Concluding remarks}

Several tidal power schemes have been proposed for the River Severn estuary between the south-west of England and Wales (see, for example, the tidal barrages summarised in Table 1). Here the Cardiff-Weston barrage has been evaluated (see the location and schematic cross-section displayed in Figures 1 and 2, respectively) using various sustainability appraisal techniques to determine its net energy output, carbon dioxide footprint and financial investment parameters, alongside some other critical technical and environmental issues. It would be located seaward of the two Severn Road crossings, involve an estimated cost of some $£ 20.9$ billion (at 2010 prices) to construct and could potentially generate some $16 \cdot 8 \mathrm{TWh} /$ year (or about $4.4 \%$ of UK electricity demand). Comparative results were also presented for the smaller, Shoots barrage scheme (previously reported by Hammond et al. (2014)) that would be located upriver of the Severn Road crossings (see again Figure 1), which is favoured by several environmental groups, because of its more benign ecological and environmental impacts. An EA of the Cardiff-Weston scheme was conducted comprising a detailed investigation into the cradle-to-site, O\&M energy consumption for the scheme by using the system boundary illustrated schematically in Figure 4. The total energy output of the scheme over its foreseen lifespan of 120 years was calculated to determine the associated EGRs and EPPs. The former was found to be around $22 \cdot 2$ (see Table 4), while the latter was estimated to be about 8.6 years. On an opportunity cost basis, the EGR rose from $22 \cdot 2: 1$ to $57 \cdot 6: 1$ (over a 120-year lifespan) with an EPP of about 7 years. Overall, the present analysis suggests that both the Cardiff-Weston and Shoots tidal barrages have relatively attractive figures of merit in energy terms.

Tidal power barrages give rise to unwanted side effects resulting in potential environmental hazards at local, regional and global scales. In a climate-constrained world (Alderson et al., 2012), the primary concern on the global scale is anthropogenic climate change, due to an enhanced greenhouse effect induced by combustion-generated pollutants (IPCC, 2013). The system boundary (see again Figure 4) was then applied for carbon dioxide accounting, and this yielded a footprint of about 9.5-11. $0 \mathrm{gCO}_{2} \mathrm{e} / \mathrm{kWh}$. In both the energy and carbon dioxide analyses, the operational requirements and emissions of the Cardiff-Weston barrage were found to have the most significant influence on the final results (accounting for around two-thirds of the emissions). It was not possible to include all the energy requirements associated with the scheme or the sources of carbon dioxide emissions from the project, such as those emanating from the manufacturing of the hydroturbines and caissons. However, they are unlikely to have a significant impact on the energy and emissions indicators estimated here. Comparison has been made with the work sponsored by the IPCC that indicates the carbon dioxide intensity of alternative power generators (Moomaw et al., 2011). This suggests that both the Cardiff-Weston and smaller Shoots tidal power schemes display attractive figures of merit in terms of their carbon dioxide footprints, comparable with that of onshore wind over their respective life cycles. But, like other energy options, the Cardiff-Weston barrage gives rise to other ecological and environmental disbenefits at a more local scale. It will lead to significant modifications to the estuarine environment of the River Severn, resulting in the loss of intertidal habitat with potentially adverse effects on local plant and animal populations, in particular birds who feed on the tidal mudflats (Post, 2013). However, many researchers acknowledge that much more information is needed on the impact of the Cardiff-Weston barrage on large-scale sediment circulation, the erosion of foreshores, biodiversity and water quality (e.g. Binnie (2016), Hooper and Austen (2013), Kadiri et al. (2012), Kirby and Retière (2009), Pethick et al. (2009), Post (2013)). Inevitably, the smaller Shoots tidal barrage (see Hammond et al. (2014)) is likely to have less severe ecological and environmental impacts than the larger Cardiff-Weston scheme.

The economics of the Cardiff-Weston tidal power scheme was evaluated in some detail, using DCF methods. This suggested that the most likely LUEC value was $14.0 \mathrm{p} / \mathrm{kWh}$ (using the HM Treasury (2003) declining TDR), which is a higher figure than that obtained by DECC (2008) - that is, using a discount rate of $8 \%$. The present best-to-worst range for the Cardiff-Weston barrage was found to be $13 \cdot 0-21 \cdot 8 \mathrm{p} / \mathrm{kWh}$ (see Table 5 and Figure 8). No allowance has been made for the cost of decommissioning the barrage in the present study; this is due to limited data being available and the longevity of the project. It also kept this study in line with other studies, such as the earlier one by the STPG (1986). The present LUEC ranges were compared to those for alternative power generators in Figure 9, where costs for the latter technologies have been taken from Gross et al. (2010). Relative to alternative power generators, this study has confirmed the conclusions of a number of earlier studies (such as that by the consulting engineers Mott MacDonald Ltd (2010)) that the electricity generated by tidal power schemes is not presently commercially attractive in comparison with these other technologies.

The HoC-ECCC (2013) investigated a new proposal by the nowdefunct company Hafren Power Ltd (see Section 1.2) to develop a variant of the Cardiff-Weston tidal power scheme slightly different 
Engineering Sustainability

Volume 171 Issue ES8
A technology assessment of the

proposed Cardiff-Weston tidal barrage,

UK

Hammond, Jones and Spevack from that studied in the present study and by the SDC (2007). Nevertheless, it is useful to review the committee's generic findings here, as they sought to examine the feasibility of the proposal in order to encourage transparency and public debate (HoC-ECCC, 2013). The committee acknowledged that such a large-scale project might contribute to decarbonising the UK energy sector, provide energy security benefits and create jobs. They received evidence on the range of the life-cycle carbon dioxide ratio (in $\mathrm{gCO}_{2} \mathrm{e} / \mathrm{kWh}$ ). This suggested an upper bound or worst case of $80 \cdot 4 \mathrm{gCO}_{2} \mathrm{e} / \mathrm{kWh}$ (HoC-ECCC, 2013), in contrast to the value of $11 \cdot 0 \mathrm{gCO}_{2} \mathrm{e} / \mathrm{kWh}$ found in the present study. On the other hand, the lower bound or best case was close to that found here $\left(9 \cdot 5 \mathrm{gCO}_{2} \mathrm{e} / \mathrm{kWh}\right)$, although it is rather higher than those found by the SDC (2007) or Woollcombe-Adams et al. (2009): 2.42 and $5 \cdot 7 \mathrm{~g}$ carbon dioxide/ $\mathrm{kWh}$, respectively. However, the committee still viewed the carbon dioxide ratio as being small in comparison with those of other power generators in the electricity mix (HoC-ECCC, 2013), thereby delivering worthwhile carbon savings.

\section{Acknowledgements}

This work is part of a programme of research at the University of Bath on the technology assessment of low-carbon dioxide energy systems and transition pathways that is supported by a series of UK research grants and contracts awarded by various bodies. In the present context, the first author (GPH) is the principal investigator and co-leader of a large consortium of nine university partners initially funded by way of the strategic partnership between E.On UK (the electricity generator) and the UK Engineering and Physical Sciences Research Council (EPSRC) to study the role of electricity within the context of 'Transition Pathways to a Low Carbon Economy’ (under Grant EP/F022832/1) over the period 2008-2012. The second author (CIJ) was funded in part under that grant before moving to the private sector. In 2012 the project was renewed with funding solely from the EPSRC under the title 'Realising Transition Pathways: Whole Systems Analysis for a UK More Electric Low Carbon Energy Future' (under Grant EP/K005316/1). All the authors are grateful for the interaction with various consortium partners. Specific responses to technical queries were provided by Hayden Arrowsmith of Lafarge Aggregates Ltd, Stephen Bool of Bridgend Borough Council in Wales (who also sat on the Severn barrage steering committee) and Katie Gillingham of the UK DECC (Office for Renewable Energy Deployment). However, the views expressed here are those of the authors alone and do not necessarily reflect the views of the collaborators or the policies of the funding bodies.

The authors' names are listed alphabetically.

\section{REFERENCES}

Alderson H, Cranston GR and Hammond GP (2012) Carbon and environmental footprinting of low carbon UK electricity futures to 2050. Energy 48(1): 96-107, http://dx.doi.org/10.1016/j.energy.2012. 04.011.

Allen SR, Hammond GP, Harajli HA et al. (2008) Integrated appraisal of micro-generators: methods and applications. Proceedings of the
Institution of Civil Engineers - Energy 161(2): 73-86, http://dx.doi. org/10.1680/ener.2008.161.2.73.

Binnie C (2016) Tidal energy from the Severn estuary, UK. Proceedings of the Institution of Civil Engineers - Energy 169(1): 3-17, http://dx. doi.org/10.1680/jener.14.00025.

Brent RJ (1996) Applied Cost-Benefit Analysis. Edward Elgar, Cheltenham, UK.

CCC (Committee on Climate Change) (2015) Meeting Carbon Budgets: Progress in Reducing the UK's Emissions - 2015 Report to Parliament. CCC, London, UK.

Chapman PF (1974) Energy costs: a review of methods. Energy Policy 2(2): 91-103.

Cheng VKM and Hammond GP (2016) Life-cycle energy densities and land-take requirements of various power generators: a UK perspective. Journal of the Energy Institute, http://dx.doi.org/10.1016/j.joei.2016. 02.003 .

Climate Change Act 2008. Chapter 27. Her Majesty's Stationery Office, London, UK

DECC (Department of Energy and Climate Change) (2008) Analysis of Options for Tidal Power Development in the Severn Estuary - Interim Options Analysis Report. DECC, London, UK.

DECC, the South West Regional Development Agency and the Welsh Assembly Government (2010a) Severn Tidal Power: Feasibility Study Conclusions and Summary Report. DECC, London, UK.

DECC, the South West Regional Development Agency and the Welsh Assembly Government (2010b) Severn Tidal Power: Potential for Compensatory Measures. DECC, London, UK.

DTI (Department of Trade and Industry) (2007) Meeting the Energy Challenge - a White Paper on Energy. The Stationery Office, London, UK.

EC (European Commission) (2007) Guidance Document on Article 6(4) of the Habitats Directive, 92/43/EEC. EC, Brussels, Belgium.

El-Fadel RH, Hammond GP, Harajli HA et al. (2010) The Lebanese electricity system in the context of sustainable development. Energy Policy 38(2): 751-761, http://dx.doi.org/10.1016/j.enpol.2009.10.020.

Elliott D (2012) Tidal power. In Renewable Energy: Power for a Sustainable Future, 3rd edn (Boyle D (ed.)). Oxford University Press, Oxford, UK, pp. 241-296.

Gross R, Blyth W and Heptonstall P (2010) Risks, revenues and investment in electricity generation: why policy needs to look beyond costs. Energy Economics 32(4): 796-804.

Hammond GP (2000) Energy, environment and sustainable development: a UK perspective. Process Safety and Environmental Protection 78(4): 304-323, http://dx.doi.org/10.1205/095758200530826.

Hammond GP and Jones Cl (2008) Embodied energy and carbon in construction materials. Proceedings of the Institution of Civil Engineers - Energy 161(2): 87-98, http://dx.doi.org/10.1680/ener. 2008.161.2.87.

Hammond GP and Jones CI (2011a) Sustainability criteria for energy resources and technologies. In Handbook of Sustainable Energy (Galarraga I, González-Eguino M and Markandya A (eds)). Edward Elgar, Cheltenham, UK, pp. 21-46.

Hammond G and Jones C (2011b) Embodied Carbon: the Inventory of Carbon and Energy (ICE) (Lowrie F and Tse P (eds)). BSRIA, Bracknell, UK, BG 10/2011.

Hammond GP and Pearson PJG (2013) Challenges of the transition to a low carbon, more electric future: from here to 2050. Energy Policy 52: 1-9, http://dx.doi.org/10.1016/j.enpol.2012.10.052.

Hammond GP and Winnett AB (2006) Interdisciplinary perspectives on environmental appraisal and valuation techniques. Proceedings of the Institution of Civil Engineers - Waste and Resource Management 159(3): 117-130, http://dx.doi.org/10.1680/warm.2006. 159.3.117.

Hammond GP, Ondo Akwe SS and Williams S (2011) Techno-economic appraisal of fossil-fuelled power generation systems with carbon 
Engineering Sustainability

Volume 171 Issue ES8
A technology assessment of the

proposed Cardiff-Weston tidal barrage,

UK

Hammond, Jones and Spevack dioxide capture and storage. Energy 36(2): 975-984, http://dx.doi.org/ 10.1016/j.energy.2010.12.012.

Hammond GP, Harajli HA, Jones $\mathrm{Cl}$ and Winnett AB (2012) Whole systems appraisal of a UK building integrated photovoltaic (BIPV) system: energy, environmental, and economic evaluations. Energy Policy 40: 219-230, http://dx.doi.org/10.1016/j.enpol.2011.09.048.

Hammond GP, Howard HR and Jones Cl (2013) The energy and environmental implications of UK more electric transition pathways: a whole systems perspective. Energy Policy 52: 103-116, http://dx.doi. org/10.1016/j.enpol.2012.08.071.

Hammond GP, Jones Cl and Spevack R (2014) The 'shoots barrage': an indicative energy technology assessment of a tidal power scheme. Journal of Sustainable Development of Energy, Water and Environment Systems 2(4): 388-407, http://dx.doi.org/10.13044/j. sdewes.2014.02.0031.

Hammond GP, Jones Cl and O'Grady A (2015) Environmental life cycle assessment (LCA) of energy systems. In Sustainability of Energy Systems (Yan J (ed.)). Wiley, Chichester, UK, Handbook of Clean Energy Systems, vol. 6, pp. 3343-3368.

Heijungs R, Guinee JB, Huppes G et al. (1992) Environmental Life-cycle Assessment of Products - Guide and Background. Leiden University, Leiden, the Netherlands, Report CML 92.

Heptonstall P (2007) A Review of Electricity Unit Cost Estimates. UK Energy Research Centre, London, UK, Working Paper UKERC/WP/ TPA/2007/006.

HM Treasury (2003) The Green Book: Appraisal and Evaluation in Central Government. The Stationery Office, London, UK.

HoC-ECCC (House of Commons Energy and Climate Change Committee) (2013) A Severn Barrage? Second Report of Session 2013-14. The Stationery Office, London, UK, HC 194.

Hooper T and Austen M (2013) Tidal barrages in the UK: ecological and social impacts, potential mitigation, and tools to support barrage planning. Renewable and Sustainable Energy Reviews 23: 289-298.

IFEU (Institut fur Energie und Umweltforschung) (2008) EcoTransIT: Ecological Transport Information Tool: Environmental Methodology and Data. IFEU, Heidelberg, Germany.

IPCC (Intergovernmental Panel on Climate Change) (2013) Climate Change 2013 - the Physical Science Basis. Cambridge University Press, Cambridge, UK.

Kadiri M, Ahmadian R, Bockelmann-Evans B, Rauen W and Falconer $R$ (2012) A review of the potential water quality impacts of tidal renewable energy systems. Renewable and Sustainable Energy Reviews 16(1): 329-341.

Kirby R and Retière C (2009) Comparing environmental effects of Rance and Severn barrages. Proceedings of the Institution of Civil Engineers Maritime Engineering 162(1): 11-26, http://dx.doi.org/10.1680/maen. 2009.162.1.11.
Kirby R and Shaw TL (2005) Severn barrage, UK - environmental reappraisal. Proceedings of the Institution of Civil Engineers Engineering Sustainability 158(1): 31-39, http://dx.doi.org/10.1680/ ensu.2005.158.1.31.

Kohyama H (2006) Selecting Discount Rates for Budgetary Purposes. Harvard Law School, Cambridge, MA, USA.

Moomaw W, Burgherr P, Heath G et al. (2011) Annex II: methodology. In IPCC Special Report on Renewable Energy Sources and Climate Change Mitigation (Edenhofer $\mathrm{O}$ et al. (eds)). Cambridge University Press, Cambridge, UK, pp. 973-1000.

Mott MacDonald Ltd (2010) UK Electricity Generation Costs: Update. Mott MacDonald, Brighton, UK.

Pethick JS, Morris RKA and Evans DH (2009) Nature conservation implications of a Severn tidal barrage - a preliminary assessment of geomorphological change. Journal for Nature Conservation 17(4): 183-198.

Post (Parliamentary Office of Science and Technology) (2007) Electricity in the UK. Post, London, UK, Postnote No. 280.

Post (2013) Environmental Impact of Tidal Energy Barrages. Post, London, UK, Postnote No. 435.

RCEP (Royal Commission on Environmental Pollution) (2000) Twentysecond Report: Energy - the Changing Climate. The Stationery Office, London, UK.

REUK (Renewable Energy UK) (2017) http://www.reuk.co.uk (accessed 10/01/2017).

Roberts F (1978) The aims, methods and uses of energy accounting. Applied Energy 4(1): 199-217.

Roberts F (1982) Energy accounting of River Severn tidal power schemes. Applied Energy 11(3): 197-213.

SDC (Sustainable Development Commission) (2007) Turning the Tide: Tidal Power in the UK. SDC, London, UK.

Slesser M (1978) Energy in the Economy. Macmillan Press, London, UK. STPG (Severn Tidal Power Group) (1986) Tidal Power from the Severn. Thomas Telford, London, UK.

STPG (1989) Severn Barrage Project: Detailed Report Volume IIIA: Civil Engineering (including Site Investigations). Department of Energy, London, UK, Contractor Report ETXU TID-4060-P3A.

Udo de Haes HA and Heijungs R (2007) Life-cycle assessment for energy analysis and management. Applied Energy 84(7-8): 817-827, http:// dx.doi.org/10.1016/j.apenergy.2007.01.012.

White SW and Kulcinski GL (2000) Birth to death analysis of the energy payback ratio and $\mathrm{CO}_{2}$ gas emission rates from coal, fission, wind and DT-fusion electrical power plants. Fusion Energy and Design 48(3-4): 473-481.

Woollcombe-Adams C, Watson M and Shaw CT (2009) Severn barrage tidal power project: implications for carbon emissions. Water and Environment Journal 23(1): 63-68.

\section{How can you contribute?}

To discuss this paper, please email up to 500 words to the editor at journals@ice.org.uk. Your contribution will be forwarded to the author(s) for a reply and, if considered appropriate by the editorial board, it will be published as discussion in a future issue of the journal.

Proceedings journals rely entirely on contributions from the civil engineering profession (and allied disciplines). Information about how to submit your paper online is available at www.icevirtuallibrary.com/page/authors, where you will also find detailed author guidelines. 